\title{
Quality of life in adolescent and young adult cancer patients: a systematic review of the literature
}

\author{
This article was published in the following Dove Press journal: \\ Patient Related Outcome Measures \\ 17 February 2015 \\ Number of times this article has been viewed
}

\section{Gwendolyn P Quinn 1-3 \\ Vânia Gonçalves ${ }^{4}$ \\ Ivana Sehovic ${ }^{1,3}$ \\ Meghan L Bowman ${ }^{1,3}$ \\ Damon R Reed ${ }^{2,3,5}$}

'H Lee Moffitt Cancer Center and Research Institute, Department of Health Outcomes and Behavior, Tampa, FL, USA; ${ }^{2}$ Morsani College of Medicine, University of South Florida, Tampa, FL, USA; ${ }^{3} \mathrm{H}$ Lee Moffitt Cancer Center and Research Institute, Adolescent Young Adult Oncology Program, Tampa, FL, USA; ${ }^{4}$ Faculty of Psychology and Educational Sciences, University of Coimbra, Coimbra, Portugal; ${ }^{5} \mathrm{H}$ Lee Moffitt Cancer Center and Research Institute, Department of Sarcoma, Tampa, FL, USA
Correspondence: Gwendolyn P Quinn Health Outcomes and Behavior, I 2902 Magnolia Drive, MRC CANCONT, Tampa,

FL 33612, USA

$\mathrm{Tel}+\mid 8137451359$

$\mathrm{Fax}+18134498019$

Email gwen.quinn@moffitt.org
Introduction: Adolescent and young adult (AYA) cancer survivors experience many unique challenges and quality of life (QoL) effects that persist beyond cancer diagnosis and treatment. Due to continuous improvements in technology and cancer treatments resulting in improved survival rates, the identification of late effects, survivorship issues, and QoL is moving to the forefront of cancer research. The goal of this systematic review was to identify key psychosocial factors impacting QoL in AYA oncology populations.

Methods: A systematic review of the literature was conducted using combinations of these phrases or keywords: "adolescent and young adult or AYA" AND "health outcomes OR quality of life OR psychology" AND "neoplasm OR cancer OR oncology". A total of 35 articles were included in this review. Studies were classified into two categories: AYA perceptions and stakeholder perceptions.

Results: AYA cancer survivors were more likely to have "worse" or impaired QoL compared with the general population, regardless of other demographic factors. AYAs described both positive and negatives experiences with their medical care, the educational information received, and the supportive care services. Although health care professionals were likely to underestimate or misjudge the health preferences and support needs of AYAs, these perceptions varied across disciplines and levels of experience.

Conclusion: The literature is lacking in sufficient evidence-based interventions to improve QoL in AYA cancer populations. Further, the tools to adequately measure QoL in this population are also unsatisfactory. The literature, however, consistently shows agreement regarding the unique needs of this population, indicating a trend toward health care standardization within age ranges or life stages. We suggest the need for AYA-specific programs in health care institutions that comprise a multidisciplinary team that addresses all the unique medical and QoL needs of AYAs.

Keywords: adolescent and young adult, oncology, quality of life

\section{Introduction}

Adolescent and young adult (AYA) cancer survivors experience many unique challenges and quality of life (QoL) effects that persist beyond cancer diagnosis and treatment, including issues with infertility, ${ }^{1,2}$ body image dissatisfaction, ${ }^{3}$ difficulty establishing relationships, ${ }^{3,4}$ and many other aspects of physical and social functioning. ${ }^{5-7}$ Health-related QoL can be defined as a broad, multidimensional concept that usually includes subjective evaluations of both positive and negative aspects of life. ${ }^{8}$ Overall, AYA cancer survivors are at least as likely or more likely to engage in risky health behaviors like smoking, alcohol use, and unprotected sex when compared with the general population. ${ }^{9,10}$ In addition, recent literature suggests that some health behaviors, 
such as a lack of physical activity, poor nutrition, lack of sun safety, and pain reliever addiction, are more common in AYA cancer survivors than in their healthy peers or siblings. ${ }^{11,12}$

While the National Cancer Institute ${ }^{13}$ and the LIVESTRONG Foundation ${ }^{14}$ define AYAs as those aged 15-39 years, definitions vary among other organizations and AYA literature, ranging from as low as 12 years ${ }^{15}$ to as high as 45 years. ${ }^{16}$ Individuals in the lower bracket of this age range are often transitioning to independence and autonomy from parents, including the development of their own social and financial responsibilities, joining the workforce, and establishing a personal set of values and goals. ${ }^{17-19}$ A cancer diagnosis during this multifaceted phase of psychosocial and physical growth can cause significant disruption to major developmental milestones, leading to reduced QoL. ${ }^{20}$ Older AYAs may experience psychological distress due to interruptions to family planning, ${ }^{21}$ romantic and/or intimate relationships, ${ }^{22}$ and accumulation of financial burdens. ${ }^{23}$

Due to continuous improvements in technology and cancer treatments resulting in improved survival rates, the identification of late effects, survivorship issues, and QoL is moving to the forefront of cancer research. Recently, there has been a focus in the literature on QoL factors impacting the AYA population and identification that these factors are vastly different from those for older cancer patients/survivors. To develop targeted, developmentally appropriate QoL interventions for AYA populations, a review of the literature is required. The identification of the most prominent factors affecting AYA cancer survivors will aid in developing meaningful and relevant programs. The goal of this systematic review was to identify key psychosocial factors impacting QoL in AYA oncology populations. Further, we examined psychosocial factors in relation to age, stakeholder perceptions, AYA perceptions, and outcomes (eg, QoL, adjustment).

\section{Methods}

\section{Search strategy and study selection}

A review was conducted using the PubMed database and PRISMA guidelines, including all peer-reviewed journals, without limits on publication date. The search terms included combinations of these phrases or keywords: "adolescent and young adult or AYA" AND "health outcomes OR quality of life OR psychology” AND “neoplasm OR cancer OR oncology”. PsycINFO and CINAHL databases were reviewed for additional articles. The following selection criteria were then applied: studies conducted exclusively with AYA survivors or stakeholders (parent[s] of AYA survivors, siblings of AYA survivors, caregivers, and health care providers working with AYA populations); outcome variables were any psychosocial factors impacting QoL in AYA populations, including perspectives from both AYA populations and stakeholders (excluded studies focusing on biological or medical outcomes, as well as studies focusing on improving research participation); studies published in the English language; and primary research (excluded review articles, conference abstracts, editorials, commentaries, correspondence, and case reports). The review was not limited to a specific age range; all primary research articles that defined the population of interest as "AYA" were eligible for inclusion. The review included mixed methods, quantitative, and qualitative studies.

A total of 97 articles were identified in the database search. Figure 1 presents a summary of the search strategy.

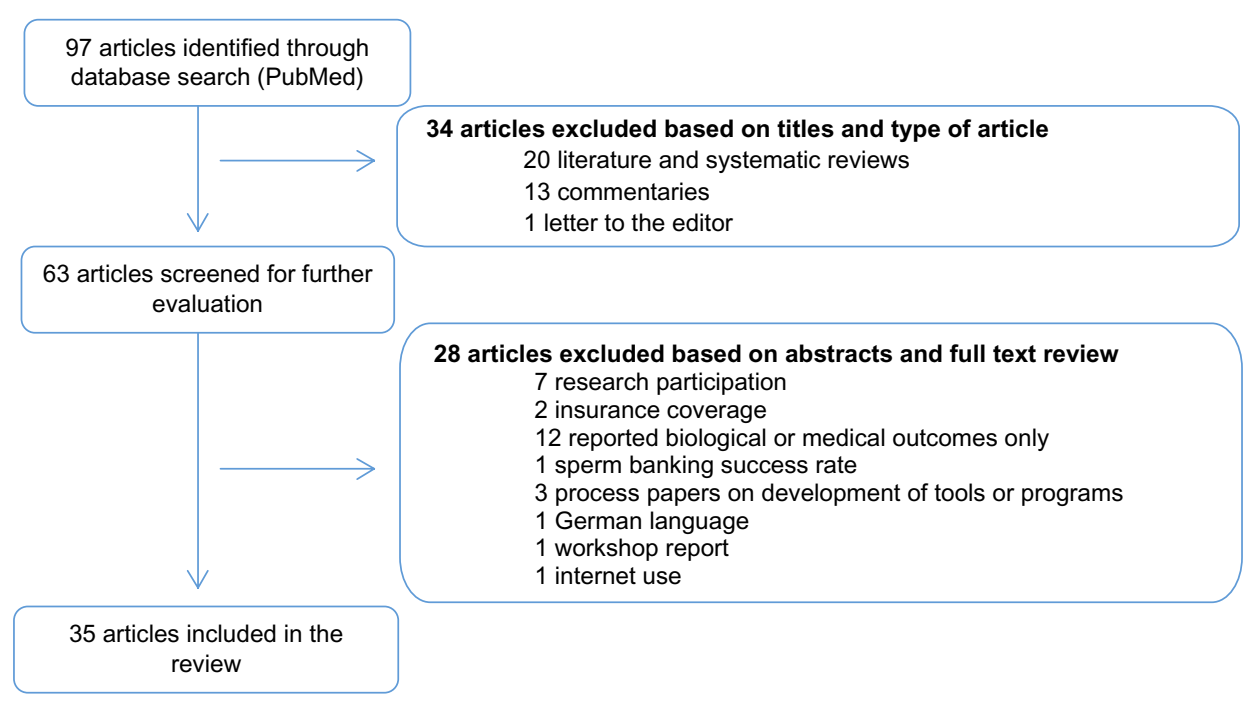

Figure I Flow diagram illustrating the search strategy for articles included in the review. 
Articles were initially screened based on title and type of article. After excluding unrelated literature and systematic reviews (20), commentaries (13), and letters to the editor (one), abstracts and full texts of 63 articles potentially meeting the inclusion criteria were screened for eligibility. Twenty-eight articles were eliminated from the review for the following reasons: strategies for improving AYA research participation (seven), insurance coverage data (two), reported only biological or medical outcomes (12), sperm banking success rate data (one), process papers on development of tools or programs (three), German language (one), report from a workshop on AYA QoL (one), and internet use data (one). The search was complemented by manually searching the reference lists of relevant articles in the databases, including reference lists of review articles focusing on AYA QoL issues. A total of 35 articles were included in this review (Table 1).

The criteria used to assess the methodological quality of qualitative research papers included in this review were based on two sets of guidelines for appraising qualitative research. ${ }^{24,25}$ Two reviewers assessed each paper for the following items: 1) clearly described aims and objectives; 2) detailed information on sampling, data collection, and analysis; 3) context of study described; 4) credible data analysis methods; 5) main results presented clearly; 6) quotations supported the results; 7) innovative and credible interpretation of results; 8) study limitations included; and 9) conclusion presented a synthesis of the study and proposed further research. Each reviewer assessed the presence or absence of these items with a rating of 0 or 1 for a maximum score of 9. Disagreements or discrepancies in scoring between reviewers were discussed until a conclusion was reached. A final assessment combining both reviewers' results placed each paper into these categories: high quality (a score of 8 or higher), medium quality (a score of 5-7), and low quality (a score of 1-4). The papers included in this review were all placed in the high or medium quality.

The criteria used to assess the methodological quality of quantitative research papers included in this review were based on two sets of guidelines for appraising quantitative research. ${ }^{26,27}$ Two reviewers assessed each paper for the following items: 1) study design identified and appropriately applied; 2) study sample representative of the group (response rate included); 3) use and appropriateness of control group; 4) confounders discussed and/or controlled; 5) valid data collection tools; 6) reliable data collection tools; 7) discussion of dropouts and study withdrawals; 8) appropriate statistical methods; and 9) influence of negative factors on study results credibility. Each reviewer assessed the presence or absence of these items with a rating of 0 or 1 for a maximum score of 9 . Disagreements or discrepancies in scoring between reviewers were discussed until a conclusion was reached. A final assessment combining both reviewers' results placed each paper into these categories: high quality (a score of 8 or higher), medium quality (a score of 5-7), and low quality (a score of 1-4). The papers included in this review were all placed in the high or medium quality.

\section{Data synthesis}

Eligible studies were classified into two categories: AYA perceptions and stakeholder perceptions. Data from each study included in this review are presented in Table 1. Key information was collected on study origin, QoL measures, definition of AYA, study population, cancer type, sample size, aims, methods, outcomes and measures, and key findings. All authors reviewed the articles and confirmed the inclusion of selected articles for this review. The information included for each article was reviewed by the authors to ensure congruence of information extracted.

\section{Results Study information}

The studies used a variety of age groupings to classify AYA. The youngest age used was 10 years and the oldest 44 years. The majority of studies used the range 15-39 years $(\mathrm{n}=9)$. The most common lower age limit was 15 years $(\mathrm{n}=15)$ and the most common upper age limit was 39 years $(n=11)$. The study populations were primarily AYA cancer survivors $(n=26)$ followed by stakeholders (clinicians or parents) $(n=5)$ and a combination of survivors and stakeholders $(n=4)$.

Nineteen studies used quantitative methods, 13 studies used qualitative methods, and three studies used mixed methods. The majority of studies examined all or most cancer types $(n=21)$. Others were specific to combinations of sarcoma, brain, and hematological cancers $(\mathrm{n}=6)$; stem cell transplant patients $(\mathrm{n}=2)$; breast and gynecological cancers $(\mathrm{n}=1)$; hematological cancer $(\mathrm{n}=5)$; and testicular cancer $(\mathrm{n}=1)$. Study stages of data collection varied from time of diagnosis, during active treatment, up to 18 years posttreatment, deceased, and unspecified stages. The sample sizes of the studies ranged from 8,375 to eight. Seven studies used the Surveillance, Epidemiology, and End Results (SEER) cancer registry with a sample size of 523 (ie, the same data set was used).

\section{Study aims}

For the majority of studies, the primary goal was to describe or characterize the QoL or psychosocial impact or examine 
Table I Articles included in the review

\begin{tabular}{|c|c|c|c|c|c|}
\hline $\begin{array}{l}\text { Authors } \\
\text { (country) }\end{array}$ & Quality of life measures & Definition of AYA & $\begin{array}{l}\text { Study } \\
\text { population }\end{array}$ & Cancer type & $\begin{array}{l}\text { Sample size } \\
\text { (M/F\%) }\end{array}$ \\
\hline $\begin{array}{l}\text { Kirchhoff } \\
\text { et } \mathrm{al}^{28} \text { (USA) }\end{array}$ & $\begin{array}{l}\text { The BRFSS includes four items known } \\
\text { as the Health Days Measure that } \\
\text { investigate QoL. Perceived sense of } \\
\text { well-being is assessed in four areas: } \\
\text { I) self-rated general health (excellent/ } \\
\text { very good/good/fair/poor); 2) number } \\
\text { of recent days (within the past } \\
30 \text { days) when physical health was not } \\
\text { good; 3) number of recent days when } \\
\text { mental health was not good; and } \\
\text { 4) number of recent activity limitation } \\
\text { days because of poor physical/mental } \\
\text { health }\end{array}$ & Age $15-39$ years & AYA survivors & All & $\begin{array}{l}\text { AYA survivors } \\
(\mathrm{N}=8,375,84 \% \mathrm{~F}) \text {; } \\
334,759 \text { controls } \\
(62 \% \mathrm{~F})\end{array}$ \\
\hline $\begin{array}{l}\text { El-jawahri } \\
\text { et a }\left.\right|^{34} \text { (USA) }\end{array}$ & $\begin{array}{l}\text { FACT-BMT (47-item self-report } \\
\text { questionnaire that measures the } \\
\text { effect of cancer therapy on multiple } \\
\text { QoL domains, including physical, } \\
\text { functional, social/family, emotional } \\
\text { well-being, and bone marrow } \\
\text { transplant-specific concerns, with } \\
\text { higher scores indicating greater QoL) }\end{array}$ & $\begin{array}{l}\text { AYA age } 18-40 \text { years, } \\
\text { middle-aged age } \\
4 I-59 \text { years, and } \\
\text { older aged } \geq 60 \text { years }\end{array}$ & AYA survivors & Chronic GVHD & $\begin{array}{l}\text { AYA survivors } \\
(\mathrm{N}=1 \mathrm{I} 5,5 \mathrm{I} \% \mathrm{~F}) \text {; } \\
\text { middle-aged } \\
(\mathrm{N}=279,43 \% \mathrm{~F}) \text {; } \\
\text { and older }(\mathrm{N}=128 \text {, } \\
37 \% \mathrm{~F})\end{array}$ \\
\hline $\begin{array}{l}\text { Zebrack et } a^{23} \\
\text { (USA) }\end{array}$ & $\begin{array}{l}\text { AYA HOPE survey mailed concluding } \\
\text { with an open-ended item in which } \\
\text { respondents were asked: "Tell us } \\
\text { anything else about your medical care } \\
\text { or experience with cancer" }\end{array}$ & Age 15-39 years & AYA survivors & $\begin{array}{l}\text { Histologically } \\
\text { confirmed invasive first } \\
\text { primary non-Hodgkin's } \\
\text { lymphoma, Hodgkin's } \\
\text { lymphoma, germ cell } \\
\text { cancer (eg, testicular } \\
\text { or ovarian), acute } \\
\text { lymphocytic leukemia, } \\
\text { or sarcoma, specifically } \\
\text { Ewing's sarcoma, } \\
\text { osteosarcoma, and } \\
\text { rhabdomyosarcoma } \\
\text { (tumors arising in the } \\
\text { central nervous system } \\
\text { were excluded) }\end{array}$ & $\begin{array}{l}\text { All AYA survivors } \\
(\mathrm{N}=523,37 \% \mathrm{~F}) \\
\text { AYA survivors who } \\
\text { completed question } \\
39(\mathrm{~N}=296,35 \%)\end{array}$ \\
\hline $\begin{array}{l}\text { Geue et al' } \\
\text { (Germany) }\end{array}$ & $\begin{array}{l}\text { Self-developed questionnaire (the } \\
\text { desire to have children, the intensity } \\
\text { of the desire for children, discussions } \\
\text { with physicians and fertility } \\
\text { specialists, and fertility preservation); }\end{array}$ & Age $18-45$ years & AYA survivors & All & $\begin{array}{l}\text { AYA survivors } \\
(\mathrm{N}=149,66 \% \mathrm{~F})\end{array}$ \\
\hline
\end{tabular}




\begin{tabular}{l} 
Study aim \\
\hline To describe the QoL \\
limitations of both older \\
and younger survivors \\
of AYA cancer and \\
differences by sex and \\
race/ethnicity
\end{tabular}

To analyze prospectively collected observational cohort data from the Chronic GVHD Consortium to examine whether the age of a patient with moderate or severe chronic GVHD is associated with major clinical outcomes such as QoL, symptom burden, functional ability, and mortality

To report how participants in the AYA HOPE survey described their medical care and experiences with cancer
I) To investigate young cancer patients' desire to have children, its intensity, and their discussion with oncologists and fertility
Methods ${ }^{\dagger}$
A: Using the 2009 BRFSS data, the study identified 8,375 individuals with cancer while aged I5-39 years and 334,759 controls. Participants were currently aged $\geq 20$ years. QoL was measured using four items from the Centers for Disease Control and Prevention's Healthy Days Measure (general health, number of days of poor physical and mental health, and activity limitation days). Multivariable regressions compared these measures for survivors and controls by sex, race/ ethnicity, and age and among survivors to determine cancer-related factors associated with poor QoL

A: Patients and clinicians reported standardized information about chronic GVHD symptoms and organ involvement at the time of study enrollment and at serial follow-up visits every 6 months. The FACT-BMT was used to assess QoL. Overall health and functioning were assessed using the Medical Outcomes Study SF-36. The Lee Chronic GVHD Symptom Scale was used to assess symptom burden of chronic GVHD

B: Patients were identified through seven $\mathrm{NCI}$ SEER program cancer registries. Participants received the AYA HOPE survey in the mail

\section{Outcomes and measures}

Survivors were more likely to report fair/poor general health than controls (relative risk $=1.92 ; 95 \% \mathrm{Cl}$ : I.77-2.10; $P<0.001$ ). QoL limitations existed by sex and race/ethnicity for survivors. Approximately $30 \%$ of survivors currently in their 40 s, 50 s, and early 60 s were in poor health, compared with less than $20 \%$ of same-aged controls (both $P<0.00 \mathrm{I}$ ). Of survivors with two or more cancers, $41.0 \%$ reported poor health, compared with $26.2 \%$ with one cancer $(P<0.00 \mathrm{I})$

Despite more physical limitations in older patients, as measured by worse functional status (shorter 2MWT $[P<0.00 I]$ and lower HAP scores $[P<0.00 I])$ relative to AYA and middle-aged patients, older patients reported better QoL (FACTBMT, $P=0.004$ ) compared with middleaged patients and similar to AYA patients $(P=0.99)$

Most AYAs expressed satisfaction with the medical care, information, and support they received. Dissatisfaction with care also emerged, particularly around a lack of information about drug effects and protocols, alternative treatment options, complementary and alternative medicine, and appropriate follow-up care upon completion of therapy. Respondents reported persistent physical side effects that they attributed to cancer treatment, and often attributed a poor mental health state to these treatment-related symptoms. Comments reflected negative emotions and ongoing struggles and fears related to cancer. Some survivors identified relationships with family and friends, church, God, and other cancer survivors as primary sources of inspiration, support, and positive outcomes, but others did not. Many participants reported on the financial problems due to their cancer experience

A: A total of I39 patients at the University Medical Center Leipzig aged between 18 and 45 years were contacted, informed about the study, and invited to participate. Patients who agreed to participate were sent a questionnaire by post. Patients at

\section{Seventy-four percent of patients had a} desire to have children at the time of diagnosis. Whereas the intensity of the desire for children increased pre- to posttreatment in childless patients, it decreased in patients who already had
Key findings

AYA cancer survivors have worse QoL compared with the general population, and these limitations persist across sex, race/ethnicity, and age

FACT-G and FACT-BMT TOI scores were comparable between AYA and older patients and significantly higher than those of middle-aged patients. U-shaped relationship between age and QoL, with middle-aged patients reporting a significantly lower QoL compared with both AYA and older patients

AYAs diagnosed with cancer described positive and negative experiences, often simultaneously, with the medical care they received. They also described ways in which cancer affected them in other key cancer survivorship domains. These patient-centered perspectives illuminated AYAs' preferences and needs, which is essential information for developing standards of care $^{53}$ and for meeting national priorities for patient-centered outcomes research $^{54}$

The desire to have children and the fertility issues involved are important for young cancer patients. Reasons for not discussing fertility aspects with oncologists and the cause of 
Table I (Continued)

\begin{tabular}{|c|c|c|c|c|c|}
\hline $\begin{array}{l}\text { Authors } \\
\text { (country) }\end{array}$ & Quality of life measures & Definition of AYA & $\begin{array}{l}\text { Study } \\
\text { population }\end{array}$ & Cancer type & $\begin{array}{l}\text { Sample size } \\
\text { (M/F\%) }\end{array}$ \\
\hline
\end{tabular}

psychological distress was measured with the Patient Health Questionnaire

\begin{tabular}{|c|c|}
\hline $\begin{array}{l}\text { Brunet et al }{ }^{36} \\
\text { (Canada) }\end{array}$ & $\begin{array}{l}\text { The ten-item Perceived Stress Scale } \\
\text { was used to assess participants' stress } \\
\text { levels. The ten-item Perceived Stress } \\
\text { Scale assesses the extent to which } \\
\text { situations in one's life are appraised } \\
\text { as stressful on a five-point Likert scale } \\
\text { ( } 0=\text { never to } 4=\text { very often). The Social } \\
\text { Provisions Scale was used to assess } \\
\text { the degree to which participants' } \\
\text { social relationships provided various } \\
\text { dimensions of social support } \\
\text { (ie, attachment, social integration, } \\
\text { reassurance of worth, reliable } \\
\text { alliance, guidance, and opportunity for } \\
\text { nurturance). Responses were recorded } \\
\text { on a four-point Likert scale (I= strongly } \\
\text { disagree to } 4=\text { strongly agree). } \\
\text { Participants also indicated if they had } \\
\text { been involved in a support group }\end{array}$ \\
\hline $\begin{array}{l}\text { Geue et a }{ }^{29} \\
\text { (Germany) }\end{array}$ & $\begin{array}{l}\text { EORTC QLQ-C30 contains five } \\
\text { function scales (physical, role, } \\
\text { emotional, cognitive, and social), } \\
\text { nine symptom scales, and a global } \\
\text { QoL scale }\end{array}$ \\
\hline
\end{tabular}

Age 15-39 years

AYA survivors

All

Age 18-39 years

AYA survivors

All

(compared

with general

population)
AYA survivors

$(\mathrm{N}=64 ; 73 \% \mathrm{~F})$ 


\begin{tabular}{l} 
Study aim \\
\hline specialists about \\
fertility; and 2) to \\
analyze sex differences, \\
differences between \\
childless patients and \\
patients with children, \\
and correlations with \\
psychological distress
\end{tabular}

I) To explore the relationships between AYAs' experiences of stress and social support resources (ie, perceived social support and support group involvement) following treatment for cancer; and 2) to examine the relationship between stress and physical activity behavior and test if social support resources are moderators of this relationship

To assess QoL in young cancer patients and to investigate sex differences.

I) Which differences exist between young cancer patients' QoL and that of the general population (age and sex matched)?

2) Which sex differences, with regard to QoL can be observed in young cancer patients? 3) Which sociodemographic factors influence QoL in young cancer patients?

Methods ${ }^{\dagger}$

the breast cancer center at the

Westend Hospital in Berlin were recruited during aftercare visits, which took place every 3 months. Study information was given via flyers and face to face with the physicians. Each patient aged between 18 and 45 years was asked to participate. Patients who were in rehabilitation between January and April 2012 in Bad Oeynhausen and Bad Oexen (German specialized rehabilitation clinics for cancer patients aged between 18 and 32 years) were informed about the study and given the flyer. The study also recruited via local press releases and relevant web pages

A: Participants were recruited through advertisements posted on four young adult cancer websites and four social media pages (ie, Facebook). The text advertisements included a brief introduction to the study, the research teams' contact information, and a link to a consent form and secure online questionnaire

A: This cross-sectional study was conducted with a cohort of cancer patients (AYA) who had completed acute medical treatments. All participants were informed about the study either in person or by mail and signed an informed consent form. The comparison group was generated from two representative German survey samples from 1998 and 20I2, with the assistance of an independent agency specialized in market, opinion and social research (USUMA GmbH, Berlin, Germany)
Outcomes and measures

children. A total of 55 patients who wanted a child (50\%) needed supportive care concerning this issue; $60 \%$ of the total sample had discussed fertility aspects with their oncologists and $20 \%$ with fertility specialists. Patients reported higher levels of satisfaction with their discussions with fertility specialists than with their discussions with oncologists. Men (56\%) underwent fertility preservation more often than did women (31\%). Female sex was the only variable predicting psychological distress, whereas parenthood, fertility preservation, and desire for children had no significant impact

Participants reported moderate levels of stress and high levels of perceived social support relative to the scale range. Half of the participants were involved in a support group. Also, participants reported an average of 241.66 minutes of total physical activity per week. Based on the correlation coefficients, stress was significantly and negatively related to perceived social support, support group involvement, and physical activity behavior. Perceived social support was significantly and positively related to physical activity behavior. The negative association between stress and physical activity was statistically significant for participants who were not involved in a social support group $(\beta=-0.48, P<0.0$ I) but not significant for those who were involved $(\beta=0.03, P=0.90)$

Compared with the general population $(\mathrm{N}=585)$, significantly poorer $\mathrm{QoL}$ $(P=0.00 \mathrm{I})$ was observed for the I I 7 young cancer patients (40 M, $77 \mathrm{~F}$ ) on all scales and items of the EORTC QLQ-C30. Analyses of variance with the factors group (AYA vs REP) and sex showed interaction effects for the physical $(P=0.012)$, emotional $(P=0.029)$, and cognitive function scales $(P=0.008)$ and fatigue $(P=0.026)$, as well as for the items insomnia $(P=0.0 \mathrm{II})$, constipation $(P=0.037)$, and financial difficulties $(P=0.026)$. The pattern of the interaction was that female cancer patients reported the lowest QoL outcomes. The same effects were found for the three calculated sum scales function, symptom, and total
Key findings

low referral rates to fertility specialists should be explored in future studies. The implementation of structured psychosocial supportive care might address the needs of highly fertility-distressed patients

Findings suggest that establishing support groups as part of psychosocial rehabilitation services may help to reduce stress and promote an active lifestyle in AYAs treated for cancer

Results clearly indicate that young adult cancer patients have a reduced QoL in comparison with the general population, even long after the treatment of their disease is complete. Women had a lower QoL than men. Age-specific interventions should be offered that lead to improvements in QoL for this age group 
Table I (Continued)

\begin{tabular}{|c|c|c|c|c|c|}
\hline $\begin{array}{l}\text { Authors } \\
\text { (country) }\end{array}$ & Quality of life measures & Definition of AYA & $\begin{array}{l}\text { Study } \\
\text { population }\end{array}$ & Cancer type & $\begin{array}{l}\text { Sample size } \\
\text { (M/F\%) }\end{array}$ \\
\hline $\begin{array}{l}\text { Kent et al }{ }^{37} \\
\text { (USA) }\end{array}$ & $\begin{array}{l}\text { Participants were asked "At this } \\
\text { time, do you feel you need more } \\
\text { information about ..." followed by a } \\
\text { list of needs, including the following } \\
\text { social information needs: “... how to } \\
\text { talk about your cancer experience } \\
\text { with family and friends" (labeled } \\
\text { TAC) "and meeting other adolescents } \\
\text { or young adult cancer patients/ } \\
\text { survivors?" (labeled MPS). Response } \\
\text { options were: "I have enough } \\
\text { information.", "I need some } \\
\text { more information.", “I need much } \\
\text { more information.”, and "Does } \\
\text { not apply.”. Having an unmet social } \\
\text { information need was defined as } \\
\text { participants reporting they needed } \\
\text { "some” or "much more” information }\end{array}$ & Age I5-39 years & AYA survivors & $\begin{array}{l}\text { See Zebrack et al }{ }^{23} \\
\text { above }\end{array}$ & $\begin{array}{l}\text { AYA survivors } \\
\text { ( } N=523,67 \% \mathrm{~F} ; 477 \\
\text { responded to the } \\
\text { TAC question and } \\
462 \text { responded to } \\
\text { the MPS question) }\end{array}$ \\
\hline $\begin{array}{l}\text { Smith et } \mathrm{al}^{31} \\
\text { (USA) }\end{array}$ & $\begin{array}{l}\text { The AYA HOPE survey } \\
\text { (the PedsQL }{ }^{T M} 4.0 \text { for individuals uP } \\
\text { to age } 25 \text { years }{ }^{55} \text { [domains: overall } \\
\text { health, physical health summary, } \\
\text { psychosocial health summary, } \\
\text { emotional functioning, social } \\
\text { functioning, and work/school } \\
\text { functioning]). The study also included } \\
\text { the PedsQL fatigue module. The study } \\
\text { used the SF- } 12 \text {, version } 2,{ }^{56} \text { to best } \\
\text { assess HR-QoL outcomes in older } \\
\text { young adults aged over } 25 \text { years. } \\
\text { Respondents were asked to indicate } \\
\text { whether they had received (before, } \\
\text { during, or after cancer treatment) } \\
\text { a variety of supportive care services }\end{array}$ & Age $15-39$ years & AYA survivors & $\begin{array}{l}\text { See Zebrack et al }{ }^{23} \\
\text { above }\end{array}$ & $\begin{array}{l}\text { AYA survivors } \\
(\mathrm{N}=523,37 \% \mathrm{~F})\end{array}$ \\
\hline $\begin{array}{l}\text { Kwak et al }{ }^{57} \\
\text { (USA) }\end{array}$ & $\begin{array}{l}\text { The BSI- } 18 \text { contains } 18 \text { self-report } \\
\text { items assessing psychological distress, } \\
27 \text { comprising a Global Symptom } \\
\text { Index, and the following three } \\
\text { subscales: depression (six items), } \\
\text { somatization (six items), and anxiety } \\
\text { (six items) }\end{array}$ & Age 14-39 years & AYA survivors & All invasive & $\begin{array}{l}\text { AYA survivors } \\
(\mathrm{N}=215,47 \% \mathrm{~F})\end{array}$ \\
\hline
\end{tabular}




\begin{tabular}{l} 
Study aim \\
\hline To identify factors \\
associated with social \\
information needs \\
among AYAs with cancer \\
and whether these needs \\
vary by their perception \\
of the impact of cancer \\
on social relationships
\end{tabular}

To examine physical, emotional, social, cognitive, and psychological functioning of AYA patients/ survivors with cancer, and to determine potential disease, demographic, health care, and symptom correlates of HR-QoL

I) To examine prevalence and changes in symptoms of psychological distress over I year after initial cancer diagnosis in AYA patients with cancer; and 2) to examine sociodemographic and clinical predictors of changes

Methods ${ }^{\dagger}$

B: Patients were identified through seven $\mathrm{NCI}$ SEER program cancer registries. Participants received the AYA HOPE survey in the mail

A: Patients were identified through seven $\mathrm{NCI}$ SEER program cancer registries. Participants received the AYA HOPE survey in the mail

A: Research staff at each participating institution monitored clinic registration rosters and subsequently approached 286 eligible patients to complete the surveys
Outcomes and measures

Approximately 25\% (I I8/477) and 43\% (199/462) of participants reported a TAC or MPS need, respectively. Participants in their 20s (vs teenagers) were more likely to report an MPS need $(P=0.03)$. Hispanics (vs non-Hispanic whites) were more likely to report a TAC need $(P=0.01)$. Individuals who did not receive but reported needing support groups were about four and I 3 times as likely to report TAC and MPS needs, respectively $(P<0.05)$. Participants reporting high symptom burden were more likely to report TAC and MPS needs $(P<0.0 \mathrm{I})$, and those reporting fair/poor quality of care were more likely to report a TAC need $(P<0.0 \mathrm{I})$. Those reporting that cancer had an impact on several key relationships with family and friends were more likely to report social information needs Overall, respondents reported significantly worse HR-QoL across both physical and mental health scales than did general and healthy populations. The greatest deficits were in limitations to physical and emotional roles, physical and social functioning, and fatigue. Teenaged patients (aged 15-17 years) reported worse physical and work/ school functioning than patients aged 18-25 years. Regression models showed that HR-QoL was worse for those in treatment, with current/recent symptoms, or lacking health insurance at any time since diagnosis. In addition, sarcoma patients, Hispanic patients, and those with high school or lower education reported worse physical health. Unmarried patients reported worse mental health Within the first 4 months of diagnosis, 60 respondents $(28 \%)$ had BSI- 18 scores suggesting caseness for distress. On average, distress symptoms exceeded population norms at the time of diagnosis, dipped at the 6-month follow-up, but increased to a level exceeding population norms at the 12-month follow-up.

A statistically significant decline in distress over I year was observed; however, the gradient of change was not clinically significant. Multivariate analyses revealed that the reduction in distress over time was primarily a function of being off treatment and involved in school or work. Notably, cancer type or severity was not associated with distress

\section{Key findings}

Social information needs are higher in AYAs diagnosed in their 20s, in Hispanics, among those reporting high symptom burden and/or lower quality of care, and in individuals not in support groups. Efforts should be made to develop interventions for AYAs in most need of social information and support

Results suggest that AYAs with cancer have major decrements in several physical and mental HR-QoL domains. Vulnerable subgroups included Hispanic patients, those with less education, and those without health insurance. AYAs also experienced higher levels of fatigue that were influenced by current symptoms and treatment. Future research should explore ways to address poor functioning in this understudied group

Findings emphasize the importance of early psychosocial intervention for distress in AYAs as well as the need to manage treatmentrelated symptoms and facilitate AYAs' involvement in work or school to the extent possible. Continued research is needed to understand how distress relates to QoL, functional outcomes, treatment, and symptom burden throughout the continuum of care 
Table I (Continued)

\begin{tabular}{|c|c|c|c|c|c|}
\hline $\begin{array}{l}\text { Authors } \\
\text { (country) }\end{array}$ & Quality of life measures & Definition of AYA & $\begin{array}{l}\text { Study } \\
\text { population }\end{array}$ & Cancer type & $\begin{array}{l}\text { Sample size } \\
\text { (M/F\%) }\end{array}$ \\
\hline $\begin{array}{l}\text { Smith et } \mathrm{al}^{6} \\
\text { (USA) }\end{array}$ & $\begin{array}{l}\text { AYA HOPE survey (the PedsQL } \\
4.0 \text {, PedsQL fatigue module, and } \\
\text { SF- } 12 \text {, version } 2 \text { [see Smith et al }{ }^{31} \\
\text { above]) }\end{array}$ & Age 15-39 years & AYA survivors & $\begin{array}{l}\text { See Zebrack et a }{ }^{23} \\
\text { above }\end{array}$ & $\begin{array}{l}\text { AYA survivors } \\
(\mathrm{N}=484,36 \% \mathrm{~F})\end{array}$ \\
\hline
\end{tabular}

$\begin{array}{ll}\text { Arpawong } & \text { A modified version of Tedeschi } \\ \text { et al }{ }^{59} \text { (USA) } & \text { and Calhoun's PTG inventory for } \\ & \text { assessing change following a traumatic } \\ & \text { event was used for this study. }{ }^{58} \text { The } \\ & \text { modified scale includes } 16 \text { items } \\ & \text { designed to measure survivors' } \\ & \text { perceived change in response to } \\ & \text { their cancer experience }\end{array}$




\begin{tabular}{ll}
\hline Study aim & Methods $^{\dagger}$ \\
\hline To examine unmet & B: Patients were identified through seven \\
service needs and HR- & NCI SEER program cancer registries. \\
QoL in the NCl's AYA & Participants received the AYA HOPE \\
HOPE survey & survey in the mail
\end{tabular}

To examine PTG and its correlates among an ethnically diverse sample of AYA cancer survivors who have recently completed treatment
I) To report on evaluation of the RIM for AYAs with cancer; and 2) to describe the exploratory RIM evaluation
B: Survivors of childhood cancer within 6 months of completing cancer therapy were recruited from three pediatric cancer centers. Participants completed a structured interview that assessed demographics, PTG, PTSS, HR-QoL, optimism, and depressive symptoms. Diagnosis/treatment information was collected from each patient's medical record. Multiple regression analyses were used to identify significant correlates of PTG

A: An exploratory evaluation of RIM was done using exploratory latent variable structural equation modeling with a combined sample from two studies of preadolescents and AYAs with cancer aged $10-26$ years
Outcomes and measures

Over one-third of respondents reported at least one unmet service need. The most common were financial $(16 \%)$, mental health (15\%), and support group (14\%) services. Adjusted models showed that having any unmet service need was associated with worse overall HR-QoL; fatigue; physical, emotional, social, and school/work functioning; and mental health $(P<0.000 \mathrm{I})$. Specific unmet services were related to particular outcomes (eg, needing pain management was associated with worse overall HRQoL and physical and social functioning $[P<0.00 I])$. Needing mental health services had the strongest associations with worse HR-QoL outcomes; needing physical/occupational therapy was most consistently associated with poorer functioning across domains The majority of survivors reported positive growth. PTG was positively associated with psychosocial functioning and PTSS and inversely associated with physical functioning and depressive symptoms. PTG was significantly lower among survivors of bone tumors (vs survivors of other cancers) and Hispanic survivors who primarily spoke English at home (vs Hispanics who primarily spoke Spanish at home and non-Hispanics). PTG was not significantly related to age, sex, optimism, cancer treatment modality, duration of treatment, or treatment intensity

Results, including goodness-of-fit indices, support the RIM as a theory with a high level of explained variance for outcomes of resilience $(67 \%)$ and self-transcendence (63\%). Variance explained for proximal outcomes ranged from $18 \%$ to $76 \%$
Key findings

Unmet service needs in AYAs recently diagnosed with cancer are associated with worse HR-QoL. Research should examine developmentally appropriate, relevant practices to improve access to services demonstrated to adversely impact HR-QoL, particularly physical therapy and mental health services

The AYA survivors commonly reported PTG in the immediate aftermath of cancer treatment. Findings regarding PTG among more acculturated Hispanic and bone tumor AYA survivors may help to inform riskadapted clinical interventions among those transitioning from active treatment to posttreatment surveillance, to mitigate negative long-term sequelae and enhance positive psychosocial adaptation from the cancer diagnosis and treatment

Findings indicate that, following confirmatory testing, the RIM may be a useful guide to developing targeted interventions that are grounded in the experiences of the AYAs

The female AYA cancer survivor group reported significantly poorer physical and mental health status than the matched controls. Relative to the noncancer control group, female AYA cancer survivors had significantly poorer scores on seven of eight mental health outcomes and were more likely to meet criteria for serious psychological distress $(O R=4.23$, $P \leq 0.00 \mathrm{I})$. The female AYA cancer
Diagnosis of breast and gynecological cancer during adolescence and young adulthood is associated with clinically important deficits in physical and mental health status. Given the young age of this cancer survivor cohort, increased attention should be devoted to minimizing these deficits 
Table I (Continued)

\begin{tabular}{|c|c|c|c|c|c|}
\hline $\begin{array}{l}\text { Authors } \\
\text { (country) }\end{array}$ & Quality of life measures & Definition of AYA & $\begin{array}{l}\text { Study } \\
\text { population }\end{array}$ & Cancer type & $\begin{array}{l}\text { Sample s } \\
\text { (M/F\%) }\end{array}$ \\
\hline $\begin{array}{l}\text { Love, Crook, } \\
\text { et } \mathrm{al}^{61} \text { (USA) }\end{array}$ & $\begin{array}{l}\text { Content analysis of de-identified } \\
\text { text-only files of full conversation } \\
\text { threads on a cancer support } \\
\text { form (identity and development, } \\
\text { including body image, reproduction, } \\
\text { romantic relationships, information } \\
\text { management, and careers) }\end{array}$ & Not defined & AYA survivors & $\mathrm{N} / \mathrm{A}$ & Unknown \\
\hline
\end{tabular}

Parsons et $\mathrm{al}^{43} \quad$ AYA HOPE survey (the PedsQL ${ }^{\mathrm{TM}}$ (USA) 4.0, PedsQL fatigue module, and SF-12, version 2 [see Smith et $\mathrm{al}^{31}$ above])

\begin{tabular}{|c|c|c|c|}
\hline Age 15-39 years & AYA survivors & $\begin{array}{l}\text { See Zebrack et } \mathrm{al}^{23} \\
\text { above }\end{array}$ & $\begin{array}{l}\text { AYA survivors } \\
\text { (total } N=463 \text {, } \\
\% \mathrm{~N} / \mathrm{A} \text {; AYA } \\
\text { survivors who } \\
\text { worked full time or } \\
\text { were students at } \\
\text { diagnosis } \mathrm{N}=388 \text {, } \\
36 \% \mathrm{~F} \text { ) }\end{array}$ \\
\hline
\end{tabular}

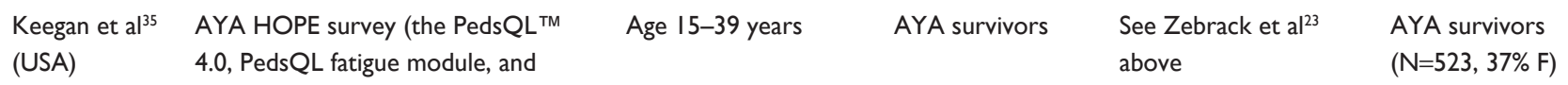
SF-12, version 2 [see Smith et al ${ }^{31}$ above]) 


\begin{tabular}{ll}
\hline Study aim & Methods $^{\dagger}$ \\
\hline & female AYA cancer survivor and \\
& noncancer control groups were compared \\
& on a range of physical and mental health \\
& status indices using analysis of covariance \\
& and binary logistic regression
\end{tabular}

To assess what is being communicated in an online community for those affected by cancer, this study addresses the research question: "What are the types of messages related to psychosocial needs being shared within the community?"

To examine the impact of cancer on work and education in a sample of AYA patients with cancer

frame included text from 350 randomly sampled posts composed of 33,040 words from 2007 to 2010 . Researchers ceased drawing additional random posts once the team reached saturation, and no new communication goals (defined as "culturally viable explanations" for behavior) emerged A: Patients were identified through seven $\mathrm{NCI}$ SEER program cancer registries. Participants received the AYA HOPE survey in the mail
To identify unmet AYA cancer survivors' information and service needs

Outcomes and measures

Key findings

survivor group also reported greater

lifetime and current prevalence of

various medical conditions, more

health-related disabilities, and greater

functional limitations than the noncancer

control group

The research team examined speech

events, noting relative frequencies

of communication goals and topics communicated by users. The

16 types of talk were grouped into five supracategories representing frequent themes: exchanging support (47.91\%), coping (24.94\%), describing experiences ( $10.81 \%)$, enacting identity (9.1\%), and communicating membership (7.37\%)
A: Patients were identified through seven $\mathrm{NCI}$ SEER program cancer registries. Participants received the AYA HOPE survey in the mail
More than $72 \%$ (282 of 388 ) of patients working or in school full time before diagnosis had returned to full-time work or school I5-35 months postdiagnosis compared with $34 \%$ (14 of 41 ) of previously part-time workers/students, $7 \%$ (one of I4) of homemakers, and $25 \%$ (five of 20) of unemployed/disabled patients $(P<0.00 \mathrm{I})$. Among full-time workers/ students before diagnosis, patients who were uninsured (OR $0.21 ; 95 \% \mathrm{Cl}$ $0.07-0.67$; no insurance vs employer-I school-sponsored insurance) or quit working directly after diagnosis (OR 0.15 ; $95 \% \mathrm{Cl} 0.06-0.37$; quit vs no change) were least likely to return.Very intensive cancer treatment and quitting work/school were associated with a belief that cancer negatively influenced plans for work/ school. Finally, more than $50 \%$ of full-time workers/students reported problems with work/studies after diagnosis

Nearly one-third of respondents indicated a need to see a mental health care professional. Need for other services ranged from $7.5 \%$ for in-home nursing care to $26 \%$ for professional assistance with health care payment. Among those indicating need, proportions of respondents indicated unmet service needs ranged from $29 \%$ for in-home nursing to $75 \%$ for a support group. In most instances, more than $50 \%$ of respondents indicating need for a service
Members of the community focused on exchanging emotional and informational support, coping with difficult emotions through expression, describing experiences of being an AYA dealing with cancer through language (metaphors), enacting identity through evaluations of the new normal (life with and after cancer), and communicating membership as an AYA with cancer

Although most AYA patients with cancer return to work after cancer, treatment intensity, not having insurance, and quitting work/school directly after diagnosis can influence work/educational outcomes. Future research should investigate underlying causes for these differences and best practices for effective transition of these cancer survivors to the workplace/ school after treatment

Recently diagnosed AYA cancer survivors have substantial unmet information needs varying by demographic and health-related factors. There are subgroups of AYA cancer survivors with high unmet needs that can be targeted for interventions and referrals 
Table I (Continued)

\begin{tabular}{|c|c|c|c|c|c|}
\hline $\begin{array}{l}\text { Authors } \\
\text { (country) }\end{array}$ & Quality of life measures & Definition of AYA & $\begin{array}{l}\text { Study } \\
\text { population }\end{array}$ & Cancer type & $\begin{array}{l}\text { Sample size } \\
\text { (M/F\%) }\end{array}$ \\
\hline
\end{tabular}

Bellizzi et al ${ }^{3} \quad$ AYA HOPE survey (the PedsQL ${ }^{\mathrm{TM}}$ (USA) 4.0, PedsQL fatigue module, and SF-12, version 2 [see Smith et $\mathrm{al}^{31}$ above])

CohenGogo et $\mathrm{a}^{42}$ (France)
The AYA unit psychologist reviewed her medical record notes concerning interviews during the last month of life and collected psychological symptoms

\section{Age 15-39 years}

AYA survivors

See Zebrack et $\mathrm{a}^{23}$ above

AYA survivors

$(\mathrm{N}=523,37 \% \mathrm{~F})$

\section{Age 13+ years}

AYA survivors

Sarcomas and brain tumors
Deceased AYA patients $(\mathrm{N}=45$, $33 \% \mathrm{~F}$ )
Cooke et $\mathrm{al}^{40}$ (USA)
A QoL model (domains: physical, psychological, social, and spiritual)
Age 18-25 years

AYA survivors

Hematological cancer

AYA survivors ( $N=24,54 \% \mathrm{~F}$ ) 
Study aim

Methods

To explore the psychosocial impact of cancer on newly diagnosed AYA cancer patients
A: Patients were identified through seven $\mathrm{NCI}$ SEER program cancer registries. Participants received the AYA HOPE survey in the mail
To provide broad baseline information about the clinical history and patterns of end of life of AYAs treated in the Pediatric and Adolescent Oncology Department at the Institut Gustave Roussy who had died in 2007-08
B: A standardized form was used to collect data concerning all 45 patients treated for a malignancy in the Pediatric and Adolescent Oncology Department at the Gustave Roussy Institute and who had died of progressive disease aged over 13 years over a 2 -year period. The investigators collected data concerning the clinical history of cancer and cancer treatment, patterns of physical symptoms during the last week of life, the care provided during the last month of life, and the cause and place of death. The AYA unit psychologist reviewed her medical record notes concerning interviews during the last month of life and collected psychological symptoms
I) To describe the allogeneic transplant experience for AYA transplant patients during the first year following transplantation, including demographic and
C: The design is a mixed-methods longitudinal clinical trial testing the effects of a standardized teaching intervention on QoL outcomes for allogeneic HCT patients at discharge and 3,6, and 12 months posthospitalization. This population was selected because

Outcomes and measures

Key findings

reported that their need had been unmet. In multivariable analyses of specific unmet needs, older participants (30-39 years vs 15-19 years) were more likely to report unmet needs related to treatments (new treatment and complementary and alternative treatment), possible long-term side effects, financial support for care, and concern about getting another type of cancer. In general, male subjects were more likely than female subjects to report unmet information needs

Respondents ( $43 \%$ response rate), on average (SD), were aged $29 \pm 6.7$ years, and most patients $(80.1 \%)$ were not receiving treatment at the time they completed the survey. With modest differences between the age groups, the most prevalent areas of life impacted in a negative way were financial, body image, control over life, work plans, relationship with spouse/significant other, and plans for having children. Endorsement of positive life impact items also was evident across the three age groups, particularly with regard to relationships, future plans/goals, and health competence The main diagnoses were sarcomas and brain tumors. Previous cancerdirected treatment included a median of three different chemotherapy regimens, high-dose chemotherapy with hematopoietic stem cell support for 13\% and radiotherapy for $40 \%$. One in every four patients had been enrolled in a clinical trial at diagnosis. Median survival was 18 months after the diagnosis and 7 months after the first relapse/ progression. During the last week of life, the median number of physical symptoms was four, mostly pain and dyspnea. Frequent psychological symptoms were sadness, anxiety, fear, and guilt. End-of-life care included transfusions, artificial nutrition, corticosteroids, pain control, and sedation, but also palliative chemotherapy. The median time spent in hospital during the last month of life was 16 days. Most patients had died in hospital Many of the patients brought up sexual concerns with the intervention nurses but felt uncomfortable with the doctor. Some of the patients expressed frustration with their fatigue. While many of the patients experienced some sad feelings, only a few met the criteria for depression. Adherence
The current results indicated that there will be future need for interventions targeting financial assistance, body image issues, relationships, and helping AYAs to attain their education objectives
Most of the patients experienced substantial physical and psychological symptoms during the last week of life. The terminally ill adolescent displays notable challenges to care providers and requires a holistic approach with the help of a multidisciplinary team
Themes that emerged within each domain were the following: sexuality/fertility, fatigue, depression/poor coping/ habits, adherence issues, use of technology, dependency issues, changes in roles/relationships, 
Table I (Continued)

\begin{tabular}{|c|c|c|c|c|c|}
\hline $\begin{array}{l}\text { Authors } \\
\text { (country) }\end{array}$ & Quality of life measures & Definition of AYA & $\begin{array}{l}\text { Study } \\
\text { population }\end{array}$ & Cancer type & $\begin{array}{l}\text { Sample size } \\
\text { (M/F\%) }\end{array}$ \\
\hline
\end{tabular}

\begin{tabular}{|c|c|c|c|c|c|}
\hline $\begin{array}{l}\text { Stern et } \mathrm{a}^{62} \\
\text { (Israel) }\end{array}$ & $\begin{array}{l}\text { The Life Orientation Test-Revised } \\
\text { (ten-item scale that measures } \\
\text { dispositional optimism); Vulnerable } \\
\text { Child Scale (I } 2 \text { items expressing } \\
\text { various concerns about AYAs' } \\
\text { health or well-being to assess the } \\
\text { relationship between perceptions } \\
\text { of vulnerability and adjustment); } \\
\text { Zimbardo time perspective inventory } \\
\text { (past negative, present, and future } \\
\text { planning); pediatric HR-QoL; }{ }^{63} \\
\text { Pediatric HR-QoL } 4.0 \text { (physical, } \\
\text { emotional, social, and school } \\
\text { functioning); career-decision making } \\
\text { difficulty questionnaire (34-item } \\
\text { scale assessing readiness, general } \\
\text { indecisiveness, lack of information } \\
\text { about career exploration, and } \\
\text { difficulties related to inconsistent } \\
\text { information) }\end{array}$ & Age 10-19 years & AYA survivors & $\begin{array}{l}\text { Lymphomas, } \\
\text { lymphoblastic, } \\
\text { leukemia, sarcomas, } \\
\text { and brain/central } \\
\text { nervous system } \\
\text { tumors }\end{array}$ & $\begin{array}{l}\text { AYA survivors } \\
(\mathrm{N}=5 \mathrm{I}, 69 \% \mathrm{~F})\end{array}$ \\
\hline $\begin{array}{l}\text { Zebrack } \\
\text { et al }{ }^{39} \text { (USA) }\end{array}$ & $\begin{array}{l}\text { Group interview ([I] "What did } \\
\text { people say or do for you that you } \\
\text { found helpful while you had cancer?"; } \\
\text { and [2] "What did people say or do } \\
\text { for you that you found harmful or } \\
\text { hurtful?") }\end{array}$ & Age $18-35$ years & AYA survivors & All & $\begin{array}{l}\text { AYA survivors } \\
(\mathrm{N}=17, \% \mathrm{~N} / \mathrm{A})\end{array}$ \\
\hline
\end{tabular}




\begin{tabular}{l}
\hline Study aim \\
treatment characteristics; \\
2) to present AYA data \\
obtained during and \\
following a six-part \\
posttransplant discharge \\
study; 3) to illustrate \\
typical AYA experiences \\
using case studies; and \\
4) to propose AYA \\
intervention strategies \\
within Erickson's \\
Stages of Psychosocial \\
Development
\end{tabular}

To examine how dispositional optimism, health vulnerability, and time perspective are related to AYA cancer survivors' CDM and QoL; and 2) to examine how cultural factors relate to CDM and QoL among IsraeliJewish and Israeli-Arab cancer survivors

To identify aspects of behavior that may promote or inhibit healthy psychosocial adjustment for this age-defined population

Methods ${ }^{\dagger}$

preliminary work provided strong evidence for their susceptibility for posthospitalization complications involving physical care and psychosocial responses. The sample is divided into participants from the intervention $(\mathrm{N}=10)$ and control $(\mathrm{N}=14)$ groups. The quantitative data consisted of demographic, treatment, mortality, readmission, and complications data. The qualitative data were obtained from patients in the intervention group $(\mathrm{N}=10)$ using information from postteaching debriefing tools, field notes, and extra session content recorded by the intervention nurses. To identify themes from the qualitative data, the investigators used the following content analysis strategies: I) analysis of interview questions; 2) extraction and identification of data from the entire corpus of the qualitative data; and 3) validation of themes between the authors

A: Potential participants meeting inclusion criteria were identified through clinic records by oncology staff at two major hospitals in Israel. All eligible participants meeting inclusion criteria were mailed an introductory letter describing the study, and were asked to return a postcard if interested in participating. Participants returned the completed packet by mail

B: Participants attending the Young Adult Survivor Conference at Camp Māk-a-Dream, a 4-day retreat for offtreatment survivors of cancers diagnosed in childhood, adolescence, or young adulthood, were offered an opportunity to voluntarily participate in a group interview in which they discussed how having had cancer has affected their lives. Investigators then organized the transcribed data into one of four a priori categories: informational, practical,
Outcomes and measures

issues with this population

centered around the mask precautions,

being on time for clinic appointments,

and medication adherence. Many patients used a great deal of technology in the hospital room and at home. Each patient had to have a dedicated caregiver throughout the transplant experience. For most of the patients, the mother was the caregiver. There were many concerns about return to school. Much of the teaching time centered on financial issues because many patients had severe financial concerns. Some of the patients experienced multiple losses during the transplant course, including friendships during transplant. Some of the families had conflicts during the transplant time.

Some patients did get support from their faith. Some verbalized fears about death. Some patients experienced benefit finding from the transplant experience Multiple regression analyses indicated that optimism, vulnerability, and past negative, present fatalistic, and future time perspectives were significantly associated with QoL $(F[6,47]=6.80, P<0.00$ I) and $\operatorname{CDM}(F[6,47]=2.46, P<0.04)$. Perceived vulnerability explained the main portion of QoL variance, with greater vulnerability associated with lowered QoL $(\beta=0.33, P<0.00$ I). Optimism was positively associated with $\mathrm{QoL}(\beta=0.55$, $P<0.02)$. Greater present fatalistic time perspective was associated with greater CDM difficulties $(\beta=0.32, P<0.05$ ). Multivariate analyses indicated greater past negative time perceptions $(F[1,46]=8.92, P<0.005)$ and fatalism about the future $(F[I, 46]=5.90, P<0.02)$ among Israeli-Arabs as compared with IsraeliJewish survivors. Israeli-Jewish survivors were more optimistic than Israeli-Arab survivors $(F[I, 46]=3.48, P<0.065)$ Survivors reported being the recipients of positive and negative communications and behaviors of an informational, practical, interpersonal, and/or emotional character. Most common were comments and actions in the interpersonal realm. More helpful than hurtful comments were reported, except in the informational category, where the "bad news" about cancer and the style of information sharing created hurt
Key findings

issues with school/education,

financial issues, family

problems/issues, miscellaneous, religion/spirituality, fear of the future, uncertainty, life, death, and more life appreciation. A coordinated and multidisciplinary approach is needed for the HCT patient who is an AYA

Vulnerability, optimism, and time perspective were significantly associated with QoL and CDM among Israeli AYA cancer survivors. IsraeliArabs viewed their pasts and futures more negatively and reported lower optimism than Israeli-Jews. Implications for future research and interventions were considered

Survivors had positive and/or negative reactions to the type and degree of communication and support they did or did not receive. They often associated positive comments and actions with useful information that helped them understand their situation and gave them an enhanced sense of control over treatment. Negative comments and actions resulted in feeling

(Continued) 
Table I (Continued)

\begin{tabular}{|c|c|c|c|c|c|}
\hline $\begin{array}{l}\text { Authors } \\
\text { (country) }\end{array}$ & Quality of life measures & Definition of AYA & $\begin{array}{l}\text { Study } \\
\text { population }\end{array}$ & Cancer type & $\begin{array}{l}\text { Sample size } \\
\text { (M/F\%) }\end{array}$ \\
\hline
\end{tabular}

Schwartz et al ${ }^{64}$ The Health Knowledge Inventory ${ }^{65}$ Age 16-29 years

(USA) (self-reported health problems in AYAs

with and without a history of cancer,

35 categories of health problems that are potential late effects of cancer treatment) and the $\mathrm{HCBl}^{66}$ (2I-item measure that assesses health-related beliefs across four factors: I) health perceptions; 2) satisfaction with health care; 3) cognitive competence; and 4) autonomy)
AYA survivors

Leukemia, lymphoma, and solid tumors

AYA survivors

$(\mathrm{N}=139,55 \% \mathrm{~F})$
Kazak et al ${ }^{33}$ The BSI-18, the HCBI, the Health

(USA)
Knowledge Inventory
Age 16-30 years

AYA survivors

Leukemia, lymphoma, and solid tumors
AYA survivors ( $N=167,53 \% \mathrm{~F})$; AYA controls $(\mathrm{N}=170,51 \% \mathrm{~F})$ 


\begin{tabular}{ll}
\hline Study aim & Methods $^{\dagger}$ \\
\hline & interpersonal/social, and/or emotional. \\
Constant comparative analysis was used \\
to identify and define themes within each \\
category
\end{tabular}

To examine the role and relationship between health problems, health competence beliefs, and posttraumatic stress and AYA cancer survivors
To compare AYA pediatric cancer survivors and peers without a history of serious illness on psychological distress, HR-QoL, and health beliefs and examine age at diagnosis and cancer treatment intensity on

Outcomes and measures

Key findings

uninformed and unable to make critical decisions, overburdened with responsibility, "like a piece of meat", "just a statistic", or "like a textbook" rather than a real young adulthood. A simple tabulation of responses suggests the importance of interpersonal support, in that friends and family members, as well as health care professionals, are often positioned to do or say things having significant and meaningful impact for these young people

A: Survivors were recruited consecutively at their annual visit to a childhood cancer survivorship clinic at a large pediatric medical facility. Informed consent or assent for those survivors aged under 18 years was obtained during the clinic visit. Of 22 I approached, I9I (86\%) consented to the study, 167 (87\% of consented) completed baseline measures during or following their clinic visit, and 139 (73\% of consented) completed follow-up measures via mail
A: AYA cancer survivors and controls were recruited during visits to a cancer survivorship clinic and primary care. Participants completed self-report questionnaires of distress, health problems, and health beliefs. For survivors, providers rated treatment intensity and health problems. The data were collected at or immediately after a medical appointment
Survivors reported a range of health problems, from 0 to 17, with an average of 5.7 (SD =3.9). PTSS, measured 2 months later using the PCL-C, ranged from 17 to 84 , with an average of 26.2 $(\mathrm{SD}=10.9)$. Seventeen survivors $(12.1 \%)$ had a score of over 40, indicating significant PTSS. In terms of meeting criteria for symptom clusters based on symptom endorsement, 33 (23.6\%) met criteria for re-experiencing, 20 (14.3\%) met criteria for avoidance, $28(20.0 \%)$ met criteria for arousal, and 14 (10.0\%) met criteria for all PTSD symptoms clusters. As expected, health problems and PTSS were significantly correlated $(r=0.44, P=0.001)$. This strong relationship held when examining the correlation of PTSS with the separate problem categories of organic/major $(r=0.3 \mathrm{I}, P=0.00 \mathrm{I})$ and constitutional/ other $(r=0.48, P=0.00 \mathrm{I})$. PTSS were not correlated with age, age at diagnosis, or time off treatment. Scores on HCBI were health perceptions (mean $=18.0$, $\mathrm{SD}=4.1$, range $=7-24$ ), cognitive competence (mean $=15.2, \mathrm{SD}=2.9$, range $=6-20$ ), autonomy (mean $=14.0$, $\mathrm{SD}=2.9$, range $=7-20$ ), and satisfaction with health care (mean $=17.4, S D=2.2$, range $=12-20$ )

There were no statistically significant differences between survivors and controls in psychological distress or HRQoL. Cancer survivors had fewer positive health beliefs. Survivors diagnosed as adolescents had significantly greater psychological distress and fewer positive health beliefs than those diagnosed earlier. Survivors with the highest level of treatment intensity had greater anxiety
The moderating role of beliefs is clinically significant; modifying beliefs to be more adaptive may mitigate the association of health problems and PTSS. As shown in interventions with childhood cancer survivors and their families, beliefs are important intervention targets that have led to promising intervention outcomes. ${ }^{67}$ Therefore, the HCBI may be useful for identifying a patient's maladaptive beliefs to inform subsequent intervention. Long term, it may be helpful to assess health competence beliefs along with PTSS and health problems as part of the standard of care in survivorship, given the prominence of these problems and the fact that beliefs are amenable to intervention

AYA cancer survivors did not differ from peers in psychological adjustment but did endorse less adaptive health beliefs. Survivors diagnosed during adolescence and who had more intensive cancer treatments evidenced poorer psychosocial outcomes. Beliefs about health may be identified 
Table I (Continued)

\begin{tabular}{|c|c|c|c|c|c|}
\hline $\begin{array}{l}\text { Authors } \\
\text { (country) }\end{array}$ & Quality of life measures & Definition of AYA & $\begin{array}{l}\text { Study } \\
\text { population }\end{array}$ & Cancer type & $\begin{array}{l}\text { Sample size } \\
\text { (M/F\%) }\end{array}$ \\
\hline
\end{tabular}

Dyson et al ${ }^{68} \quad$ Beck Depression Inventory-Fast (USA) Screen, STAI-S, and the Supportive Care Needs Survey
O'Callaghan Semi-structured interview (music et a ${ }^{69}$ (USA)

\section{preferences, music usage and}

effects before and since diagnosis, hospital sounds, whether music has a spiritual connection, music therapy experiences, and other questions to extend and clarify novel descriptions about music)
Age 16-30 years

AYA survivors

Sarcoma and hematological
AYA survivors

$(\mathrm{N}=53,74 \% \mathrm{~F})$
AYA survivors

$(\mathrm{N}=12,58 \% \mathrm{~F})$ organ tumors (four), leukemia, melanoma, pineal germinoma, and metastatic disease
Semi-structured qualitative interview (impact of testicular cancer on their romantic and sexual relationships)
Age I5-34 years

AYA survivors

Testicular

AYA survivors $(\mathrm{N}=2 \mathrm{I}, 0 \% \mathrm{~F})$ 


Study aim
these outcomes; and
2) to examine
relationships between
number of health
problems and the
outcomes

To explore psychological distress and unmet needs in AYA with cancer and identify predictors of distress among demographic and illness characteristics and supportive care needs
To examine AYA testicular cancer survivors' subjective understanding of the impact of cancer in adolescence and young adulthood, with a

\section{Methods ${ }^{\dagger}$}

A: Patients completed a cross-sectional survey, administered shortly after presentation to an AYA oncology service and within 4 months of diagnosis. Level of distress-related symptomatology in this population was based on previous work, whereby a cutoff score of 4 or greater was used for the Beck Depression Inventory-Fast Screen, and one SD above the sample population mean was used for the STAI-S

B: The AYAs participated in an audiorecorded semi-structured interview that included questions about music preferences, music usage and effects before and since diagnosis, hospital sounds, whether music has a spiritual connection, and music therapy experiences, and other questions to extend and clarify novel descriptions about music. Paraphrasing was included to corroborate the interviewer's interpretations. Thematic analysis was applied to transcribed interviews, assisted by data management software
Outcomes and measures

and fewer positive health beliefs than those with less intense treatments. Provider report of current health problems related to survivors' beliefs and mental HR-QoL only, whereas patient report of health problems correlated significantly with most psychosocial outcomes and beliefs Prevalence of distress (25\%) was lower than that found previously in AYAs with cancer. Physical and daily living needs were the most frequently unmet needs overall, followed by psychological needs, health system and information needs, and care and support needs. Lastly, being pretreatment predicted increased depression and state anxiety, while having treatment postsurgery predicted reduced state anxiety. After controlling for treatment status, however, the main predictors of depression and state anxiety were physical and daily living needs and health system and information needs, respectively

Analysis yielded 752 codes, 13 categories, and five themes. The five category groups were condensed into five corresponding themes as follows: theme A: AYAs' music backgrounds affect their musical experiences and reflections about their lived lives; theme B: AYAs' "normal" development alongside cancer's biopsychosocial impact changes their "musicking" mildly to profoundly; theme C: "musicking" signifies and promotes AYAs' endurance and identity adjustment through treatment and recovery, expressed in cognitive, emotional, physical, and imagery responses; theme

D: some AYAs find that time with flexible music therapists promotes normality, fun, and/or support; and theme E: wisdom: sound and music-based support strategies that include flexibility and choice are recommended for health care providers and other AYAs

B: AYA testicular cancer survivors were recruited from outpatient testicular cancer follow-up clinics and completed a semi-structured qualitative interview that assessed the impact of testicular cancer on their romantic and sexual relationships
The inductive thematic analysis resulted in I 8 categories, which were subsequently grouped into four key themes: I) embarrassment leads to delays in care seeking; 2) testicular cancer makes you feel different from others; 3 ) being different from others makes you damaged
Key findings

and targeted for intervention to improve QoL, particularly when patient perceptions of current health problems are considered

Lower levels of distress and unmet psychological needs were related to the few participants (I7\%) in this study who were pretreatment, when distress was most likely. However, physical needs and information needs, which are almost inevitable throughout treatment and beyond, were more important predictors of distress. Further exploration must consider the psychosocial difficulties underlying this association and the needs of AYAs at transitions between critical periods in their cancer journey (ie, upon diagnosis and during treatment)

Participants mostly reported music's calming, supportive, and relaxing effects, which alleviated hardship associated with their cancer diagnoses. Music provided supportive messages, enabled personal and shared understandings about cancer's effects, and elicited helpful physical, emotional, and imagery states. Music therapy could also promote normalized and supportive connections with others. A musician, however, struggled to get music "back" posttreatment. Music can signify and creatively enable AYAs' hope, endurance, identity development, and adjustment through cancer treatment and posttreatment phases

Four themes were identified that reflected survivors' understanding of the impact of cancer in adolescence and young adulthood: I) embarrassment leads to delays in care seeking; 2 ) testicular cancer makes you 
Table I (Continued)

\begin{tabular}{|c|c|c|c|c|c|}
\hline $\begin{array}{l}\text { Authors } \\
\text { (country) }\end{array}$ & Quality of life measures & Definition of AYA & $\begin{array}{l}\text { Study } \\
\text { population }\end{array}$ & Cancer type & $\begin{array}{l}\text { Sample size } \\
\text { (M/F\%) }\end{array}$ \\
\hline
\end{tabular}

Casillas et $\mathrm{al}^{4} \quad$ Individual key informant interviews

(USA) for AYA survivors (guided by open-

ended questions on personal narrative and transitional experience) and semistructured focus group interviews for parents of AYAs (open-ended questions regarding barriers and facilitators to survivorship care in the adult-centered health care setting)
Age 15-30 years

AYA survivors
and stakeholders
(parents of AYAs)
Leukemia, brain/ central nervous

system, lymphomas, soft-tissue sarcoma
AYA survivors $(\mathrm{N}=27,56 \% \mathrm{~F})$; stakeholders $(\mathrm{N}=21,67 \% \mathrm{~F})$
Santacroce and Crandell ${ }^{30}$ (USA)
Psychological distress was measured with the BSI-I 8 form ${ }^{71}$. Cancer-related PTSS were measured with the University of California at Los Angeles PTSD Reaction Index. ${ }^{72}$ Health behavior was measured with the Health Promoting Lifestyle Index ${ }^{73}$
Age 15-29 years

AYA survivors

and stakeholders

(childhood cancer survivors and their AYA biological siblings)
All

AYA survivors

$(\mathrm{N}=8,25 \% \mathrm{~F})$; AYA survivors' siblings $(\mathrm{N}=8,50 \% \mathrm{~F})$ 


Study aim
particular emphasis on
romantic and sexual
relationships

To determine Latino AYA cancer survivors' perceived barriers or facilitators to transition from pediatric to adultcentered survivorship care and to also assess the parents' perspective of care

\section{Methods ${ }^{\dagger}$}

Outcomes and measures

goods; and 4) cancer disclosure is difficult. These four themes were identified as patterned responses or meanings within the data set and captured something important about the data in relation to the research question of interest

B: The study was cross-sectional and recruited participants from the greater Los Angeles area. Qualitative data were collected using key informant interviews with Latino AYA survivors and focus groups with Latino parents of AYA survivors
Both AYA survivors and parents identified two major facilitative factors for survivorship care: involvement of the nuclear family in the AYA's survivorship care in the adult health care setting and including symptom communication in late effects discussions. Barriers to care included perceived stigma of a cancer history and continued emotional trauma related to discussions about the childhood cancer experience
I) To assess the feasibility of studying allostatic load in AYA cancer populations; and 2) to briefly describe preliminary findings about psychological distress, cancer-related PTSS, health behavior, and allostatic load in AYA survivors and their siblings in the context of a small pilot study
A: The study used a two-group design: AYA (age 15-29 years) childhood cancer survivors and their AYA (age 15-29 years) biological siblings. Participation involved one study visit (45-60 minutes), where participants were asked to complete a set of standardized questionnaires and provide blood samples and salivary samples. Participants took an additional four salivary samples at home. Measurement of allostatic load was guided by the work of Seeman et $\mathrm{al}^{74}$
Overall, survivor and sibling groups both tended to have greater psychological distress than community norms. Each group had a mean value that was close to the 80 th percentile in community samples. Furthermore, two (25\%) survivors and three $(37.5 \%)$ siblings met the case definition for psychological distress: ie, they were above the 90th percentile for community norms on either the BSI total score and/or two of the BSI subscales. ${ }^{71}$ On the measure of symptoms of cancer-related PTSS, at least four (50\%) participants from each group either had a score that fell within the moderate (25-39) severity level or met full symptom criteria for cancer-related
Key findings

feel different from others; 3) being different from others makes you damaged goods; and 4) cancer disclosure is difficult. As these themes represent important components of being in a romantic/sexual relationship, either currently or in the future, AYA testicular cancer survivors would benefit from the development of tailored interventions focused on improving these relevant domains

Barriers to survivorship care include cancer stigma for both patient and nuclear family, which can impact on seeking survivorship care due to constraints placed on discussions because it remains difficult to discuss cancer years later. Future research can evaluate whether these findings are unique to Latino childhood cancer survivors or are found in other populations of AYA cancer survivors transitioning to adult-centered health care. This communitybased participatory research collaboration also highlights the opportunity to learn about the needs of childhood cancer survivors from the lens of community leaders serving culturally diverse populations These findings illustrate the adverse psychological and physiological effects of chronic stress in the study sample, and suggest the need for further studies of the impact of childhood cancer-related stress on allostatic load and risk for future cardiovascular disease in both AYA survivors and their siblings. Survivors and siblings tended to be similar in health behaviors despite the survivors' treatment-related risk for future health problems, which was not an issue for the sibling group 
Table I (Continued)

\begin{tabular}{|c|c|c|c|c|c|}
\hline $\begin{array}{l}\text { Authors } \\
\text { (country) }\end{array}$ & Quality of life measures & Definition of AYA & $\begin{array}{l}\text { Study } \\
\text { population }\end{array}$ & Cancer type & $\begin{array}{l}\text { Sample s } \\
\text { (M/F\%) }\end{array}$ \\
\hline $\begin{array}{l}\text { Love et } \mathrm{al}^{75} \\
\text { (USA) }\end{array}$ & $\begin{array}{l}\text { A qualitative content analysis of } \\
\text { messages related to nutrition and } \\
\text { exercise posted on an online young }\end{array}$ & Age 18-39 years & $\begin{array}{l}\text { AYA survivors } \\
\text { and stakeholders } \\
\text { (caregivers) }\end{array}$ & All & Unknown \\
\hline
\end{tabular}

Zebrack et $\mathrm{al}^{44}$ (USA)

Burns et $\mathrm{al}^{76}$ (USA)
Three iterative rounds of mailed surveys to AYAs and stakeholders with slightly different wording between groups (biomedical and/or psychosocial needs for AYAs at diagnosis and during treatment and for young adults who are offtreatment survivors, and an idea or vision of what optimal cancer care for AYAs should be)

100-day post-SCT interview (a single, broad, data-generating question was asked: "Please tell me about your experience of having your AYA participate in the TMV intervention.")

$\begin{array}{ll}\text { Age I8-44 years } & \text { AYA survivors } \\ & \text { and stakeholders } \\ & \text { (oncology health } \\ & \text { professionals) }\end{array}$

Brain tumor, breast cancer, endometrial, germ cell, testicular ovarian, sarcomas, Hodgkin's lymphoma, leukemia, and melanoma
AYA survivors $(\mathrm{N}=37, \% \mathrm{~F} / \mathrm{N})$; oncology health professionals $(\mathrm{N}=40, \% \mathrm{~F} \mathrm{~N} / \mathrm{A})$

\section{Age |3-2| years \\ Stakeholders \\ SCT} (parents of AYAs)
Stakeholders ( $N=7$, four mothers) 


\begin{tabular}{l} 
Study aim \\
\hline To describe topics, \\
needs, and concerns \\
related to nutrition and \\
exercise that adolescents \\
and young adults affected \\
by a serious illness \\
(cancer) discuss online
\end{tabular}

To identify important health and supportive care needs for AYA patients and survivors
B: Investigators conducted a qualitative content analysis of messages related to nutrition and exercise posted on an online young adult cancer forum

C: Over three iterative rounds of mailed surveys, participants identified, rank ordered, and rated the importance of various items
To examine parents' perspective of their AYAs' experience with SCT and involvement in a TMV intervention
B: The TMV intervention is a six-session intervention structured to accommodate the anticipated occurrence of treatmentrelated adverse effects such as fatigue, pain, and mucositis by clustering active intervention activities during the first three sessions and more passive activities during the last three sessions. During sessions $1-3$, participants engaged in music selection, lyric writing, discussion, and digitally recording their song. During sessions 4-6, participants chose photos and artwork for their project, designed the video using storyboard worksheets, and viewed the completed music video. A board-certified music therapist compiled the project for participants based on their storyboards and then transferred the final product to a videotape. Parents' interviews were conducted 100 days after transplantation. Sessions were audio taped, transcribed, and analyzed using Colaizzi's phenomenological analysis ${ }^{77}$

\section{Outcomes and measures $\quad$ Key findings}

PTSD. On the measure of health behavior, the means for survivors and siblings tended to not be distinct AYAs described several functions achieved through nutrition and exercise, such as fighting cancer, losing weight, obtaining nutrients despite side effects of treatment, promoting general health, enjoyment, and promoting mental/ emotional health. AYAs also discussed several problems that interfere with nutrition and exercise goals, such as side effects of steroids, physiological problems with eating, safety concerns or physical limitations due to treatment, poor followthrough with behavioral change, stress, and low energy

Overall, there was general agreement among health care providers and young adult survivors, with some notable exceptions. Providers and young adult survivors agreed on the relative importance of having adequate health insurance and oncology care that addresses the unique developmental characteristics of this population. Compared with health professionals, young adults ranked the importance of opportunities to meet other young adult survivors at a relatively higher level, and they also ranked those opportunities higher than the importance of support from family and friends

The investigators analyzed more than 350 significant statements from seven parents. Seven theme categories emerged: I) humbling, humiliating, horrible: parents' perspectives on the cancer experiences and SCT; 2) gratitude for the benefits of TMV intervention; 3) enhanced communication; 4) connectedness; 5) watching my AYA change and grow; 6) process of parent gaining insight; and 7) an ironic recognition of both the sad and beautiful: parents' responses to the TMV intervention
AYAs discuss specific ways nutrition and exercise help achieve a variety of functions that may be physical or psychological, cancer specific, or general. AYAs describe several concerns and barriers that impede their nutrition and exercise goals

These findings provide oncology professionals and young adults with insight into the others' values and perspectives. These findings also suggest areas in which to target investments of resources to promote quality health care and appropriate informational and supportive care services and to overcome the deficit in survival improvement that has occurred in young adults and older adolescents with cancer

Parents perceived the TMV intervention as beneficial for their AYAs in several ways, including decreased symptom distress, enhanced sense of control, and connectedness with others. From parents' perspectives, the TMV intervention fostered important communication and connectedness. Parents' narratives suggest that the TMV intervention is a way to buffer the challenges related to SCT, and a larger study is warranted 
Table I (Continued)

\begin{tabular}{|c|c|}
\hline $\begin{array}{l}\text { Authors } \\
\text { (country) }\end{array}$ & Quality of life measures \\
\hline $\begin{array}{l}\text { Clinton- } \\
\text { McHarg } \\
\text { et } \mathrm{al}^{78} \\
\text { (Australia) }\end{array}$ & $\begin{array}{l}\text { Web-based value-weighting } \\
\text { questionnaire (indicate how they } \\
\text { would allocate } 100 \text { units of funding } \\
\text { among various research approaches, } \\
\text { areas, and populations) }\end{array}$ \\
\hline
\end{tabular}

Doshi et al ${ }^{46}$ (USA)
The HCBI, BSI- $18,{ }^{71}$ STAI, ${ }^{79}$ PCL-C, ${ }^{80}$ and SF-I $2^{81}$ (I2-item measure of health status and QoL)
Docherty et $\mathrm{a}^{82}$ (USA)
A semi-structured, open-ended interview to obtain parental perspectives on the helpfulness and meaningfulness of a behavioral health music therapy intervention targeted to AYAs with cancer undergoing SCT
Age 16-29 years

childhood cancer
survivors)

\begin{tabular}{llll} 
Definition of AYA & $\begin{array}{l}\text { Study } \\
\text { population }\end{array}$ & Cancer type & $\begin{array}{l}\text { Sample size } \\
(\mathbf{M} / \mathbf{F} \%)\end{array}$ \\
\hline Not defined & $\begin{array}{l}\text { Stakeholders } \\
\text { (health care }\end{array}$ & Hematological & $\begin{array}{l}\text { Stakeholders } \\
(\mathrm{N}=127,112 \text { health }\end{array}$ \\
& providers, & & care providers, \\
& researchers, & & researchers, and \\
and other & & other professionals \\
& and 45 patients and \\
& and 45 patients & carers)
\end{tabular}

and carers)

$\begin{array}{lll}\begin{array}{l}\text { Stakeholders } \\ \text { (mothers of AYA }\end{array} & \begin{array}{l}\text { Leukemia, lymphoma, } \\ \text { and solid tumors }\end{array} & \text { Stakeholders } \\ \text { childhood cancer } & & \mathrm{N}=134 \text { families; } \\ \text { survivors) } & \text { mothers only } \\ & \mathrm{N}=101 \text {, fathers only } \\ & \mathrm{N}=21, \text { both parents } \\ & \mathrm{N}=24) \text {. Eighty-six } \\ & (76 \%) \text { mothers } \\ & \text { and } 23(70 \%) \\ & \text { fathers completed } \\ & \text { the questionnaire } \\ & \text { packet. Only } \\ & \text { maternal data } \\ & \text { were used for the } \\ & \text { primary statistical } \\ & \text { analyses }\end{array}$

Stakeholders All Parents of AYA

(parents of AYAs) survivors $(\mathrm{N}=16)$ 


\begin{tabular}{l} 
Study aim \\
\hline To quantify the \\
stakeholders' \\
perceptions about \\
how resources should \\
be allocated to best \\
improve outcomes for \\
AYA patients and their \\
families
\end{tabular}

To provide an initial report about a measure of parent beliefs regarding their health and related competencies while examining the relationship among beliefs, parent distress, and aspects of the AYA as initial evidence for the measure's validity

To describe parental perspectives on the helpfulness and meaningfulness of a behavioral health music therapy intervention targeted to AYAs with cancer undergoing SCT

\section{Methods ${ }^{\dagger}$}

A: Participants were invited to complete a web-based value-weighting questionnaire and indicate how they would allocate 100 units of funding among various research approaches, areas, and populations

A: This study was part of a larger prospective investigation of long-term outcomes of childhood cancer survivors. ${ }^{33}$ For this report, participants were parents who accompanied their 16- to 29-yearold child to an oncology follow-up clinic appointment. During the visit, parents were administered a questionnaire packet that included a demographic questionnaire, the parent $\mathrm{HCBI}$, three measures of psychological distress, and a measure of health status and QoL. Parents completed and returned the questionnaire packet during their clinic visit. Due to sample size considerations, only maternal data were used for the primary statistical analyses

B: A qualitative descriptive design was used to obtain parents' perspectives. A maximum variation purposive sampling technique was used to sample 16 parents whose AYA had been randomized to the intervention group. A semi-structured, open-ended interview was conducted between 100 and 160 days after the AYA's transplant
Outcomes and measures

Eighty participants (5I\%) completed the questionnaire. Strategic research was allocated a significantly higher proportion of funding than investigator-driven research. For research areas, clinical medicine and psychosocial research were allocated the highest proportion of funding. Within research populations, AYAs who were newly diagnosed, relapsed, or finished treatment were allocated the largest proportion of funds. Psychosocial research that focused on identifying risk and resilience, developing psychosocial measures, translating research into practice, and improving the treatment center was allocated funding slightly above other items. However, the difference was not significant

Pearson correlations among the four scales were low to moderate, ranging from a low of 0.25 to a high of 0.43 (median =0.32). The parent $\mathrm{HCBI}$ scales correlated significantly with measures of psychological distress; more positive beliefs of health-related competence were generally associated with less psychological distress. Pearson correlations were low to moderate, ranging from a low of $0.3 \mathrm{I}$ to a high of 0.59 (median $=0.43)$. Mothers' reports on each of the parent $\mathrm{HCBI}$ scales were not significantly correlated with the AYA child's age of diagnosis; there was no significant relationship between scores on the parent $\mathrm{HCBI}$ scales and an objective rating of their child's treatment intensity

Results were grouped into three categories: I) helpfulness and meaningfulness of the intervention to AYA adjustment to the transplantation experience (myriad of intervention mechanisms to reduce AYA suffering, myriad of benefits through TMV process, and power of intervention to enhance connectedness among AYA, health care providers, family, and friends); 2) helpfulness and meaningfulness of the intervention for parents (myriad of intervention mechanisms to alleviate parent suffering; AYA's digital video disk as a legacy and source of insight, pride, and joy for parents; and TMV

\section{Key findings}

Perceptions of research funding allocation in this study are in contrast to the current funding allocations of some organizations, suggesting that a review of research funding allocation may be warranted. The value-weighting approach represents an acceptable and feasible way to quantify stakeholders' perceptions about research resource allocation

This study provides preliminary evidence that the parent $\mathrm{HCBI}$ is a reliable, valid, and feasible self-report method for assessing the beliefs of parents (particularly mothers) of AYA childhood cancer survivors. Maternal beliefs about health care were related to mothers' well-being. Yet little is known about how and to what extent parental involvement is adaptive or inhibiting for their offspring's development and autonomy ${ }^{83}$ and how it may impact their child's health care. Such beliefs are likely to be amenable to interventions that help eliminate barriers to optimal health care utilization and health promotion Parents observed and interacted with their AYA who participated in a targeted behavioral intervention. Thus, parents were able to describe mechanisms through which the intervention was helpful and meaningful for the AYA and indirect personal benefits for themselves. The results suggest the importance of the targeted outcomes identified in the RIM and mechanisms of action in the Contextual Support Model of Music Therapy, and identify approaches for future study

(Continued) 
Table I (Continued)

\begin{tabular}{|c|c|c|c|c|c|}
\hline $\begin{array}{l}\text { Authors } \\
\text { (country) }\end{array}$ & Quality of life measures & Definition of AYA & $\begin{array}{l}\text { Study } \\
\text { population }\end{array}$ & Cancer type & $\begin{array}{l}\text { Sample size } \\
\text { (M/F\%) }\end{array}$ \\
\hline
\end{tabular}

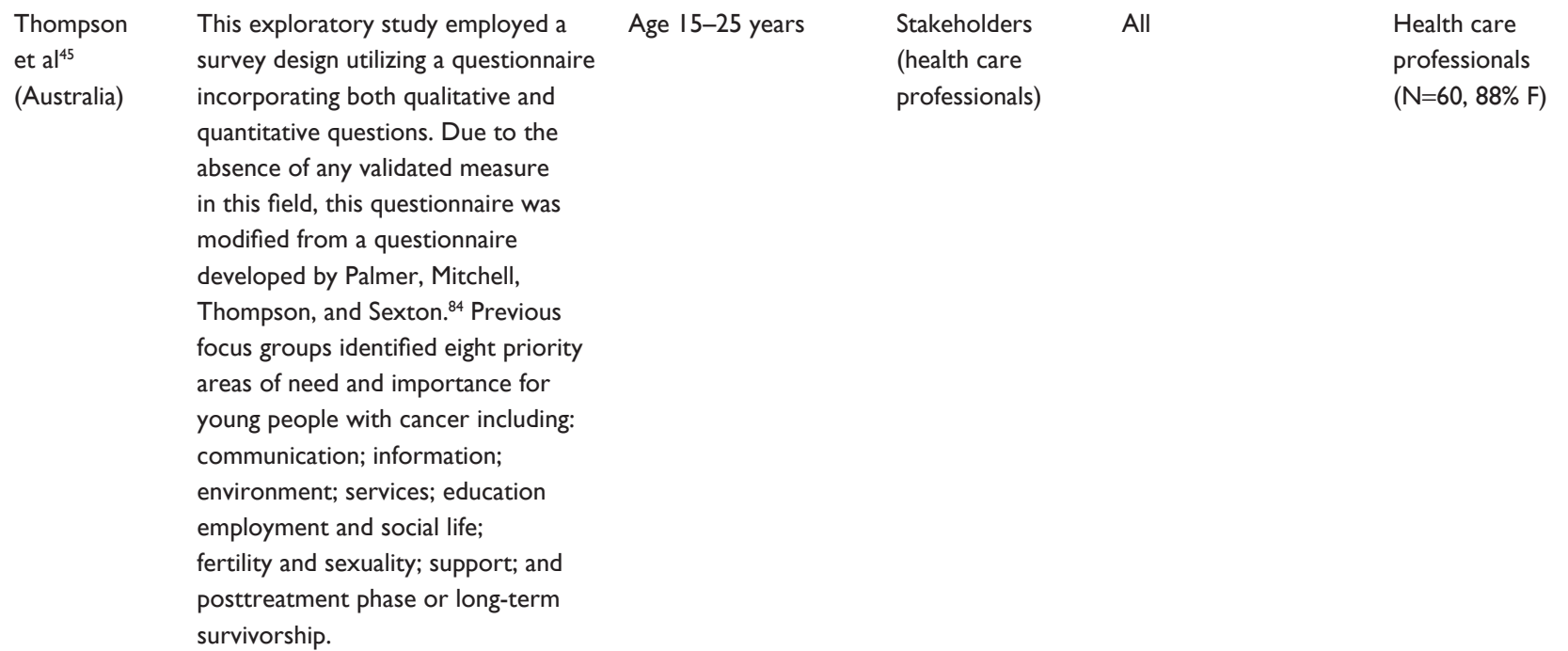

Note: ${ }^{\top}$ Type A: quantitative methods; type B: qualitative methods, type C: mixed methods.

Abbreviations: AYA, adolescent and young adult; M, male; F, female; BRFSS, Behavioral Risk Factor Surveillance System; QoL, quality of life; Cl, confidence interval; FACT-BMT, Functional Assessment of Cancer Therapy-Bone Marrow Transplantation; GVHD, graft-versus-host disease; SF-36, 36-Item Short-Form Health Survey; 2MWT, 2-minute walk test; HAP, Human Activity Profile; HCT, hematopoietic cell transplantation; FACT-G, Functional Assessment of Cancer Therapy - General; TOI, trial outcome index; AYA HOPE, Adolescent and Young Adult Health Outcomes and Patient Experience Study; NCl, National Cancer Institute; SEER, Surveillance, Epidemiology, and End Results; EORTC QLQ-C30, European Organization for the Research and Treatment of Cancer Quality of Life Questionnaire-Core 30; TAC, talk about cancer; MPS, meet peer survivors; SF-12; I2-Item Short-Form Health Survey; HR-QoL, health-related quality of life; BSI-I8, Brief Symptom Inventory-I8; PTG, post-traumatic growth; PTSS, posttraumatic stress symptoms; RIM, Resilience in Illness Model; OR, odds ratio; N/A, not applicable; SD, standard deviation; CDM, career decision making; HCBI, Health Competence Beliefs Inventory; PCL-C, Posttraumatic Stress Checklist-Civilian Version; PTSD, posttraumatic stress disorder; REP, representative sample; STAI-S, State-Trait Anxiety Inventory-State Form; SCT, stem cell transplant; TMV, therapeutic music video.

need for information or social support in relation to QoL of AYA survivors $(n=16)$. Two studies examined QoL in relation to fertility and sexuality. Four studies examined QoL in relation to theoretical models or constructs (posttraumatic stress disorder, positive growth, optimism, and resilience). ${ }^{1,40}$ Four studies examined parents' perceptions of their AYA son's or daughter's QoL. Provider perceptions of AYA QoL were explored in two studies. Two studies inspected QoL in AYA transplant populations. The remaining studies examined QoL of AYA compared with matched healthy controls $(n=1)$, work and education $(n=1)$, end-of-life issues $(n=1)$, and the impact of music $(n=1)$.

\section{AYA perceptions}

AYA cancer survivors were more likely to have "worse" or impaired QoL compared with the general population, regardless of other demographic factors. ${ }^{28-33}$ However, AYA transplant patients reported QoL equal to or better than older transplant patients. ${ }^{34}$ AYAs described both positive and negatives experiences with their medical care, the educational information received, and the supportive care services. , $23,35-39$ Respondents typically wanted more information about side effects, alternative treatment options, fertility and childbearing options, and long-term survivorship care. ${ }^{1,23,35,40}$ Females were more likely to report distress or poor QoL related to fertility issues. ${ }^{1,29}$ AYAs reported ongoing struggles and fears related to the cancer experience, including financial problems and negative emotions related to death, body image, and perceived stigma. ${ }^{3,11,40,41}$ Terminally ill AYAs in particular experienced substantial physical and psychological symptoms throughout end-of-life stages. ${ }^{42}$ Treatment type, lack of insurance, and quitting school or work after diagnosis had a negative impact on work/educational outcomes for survivors. ${ }^{3,43}$ Relationships with family, friends, other cancer 


\begin{tabular}{|c|c|c|c|}
\hline Study aim & Methods ${ }^{\dagger}$ & Outcomes and measures & Key findings \\
\hline $\begin{array}{l}\text { To explore oncology } \\
\text { professionals' } \\
\text { understanding of the } \\
\text { health care preferences } \\
\text { of AYAs with cancer } \\
\text { receiving treatment at a } \\
\text { specialist cancer center }\end{array}$ & $\begin{array}{l}\text { C: Participants were invited to complete } \\
\text { the survey through multidisciplinary } \\
\text { tumor stream meetings. Inclusion criteria } \\
\text { included being an employee of Peter } \\
\text { Mac; working within the AYA cancer } \\
\text { service, medical, nursing, or allied health } \\
\text { fields; working in tumor streams where } \\
\text { there was a recognized volume of young } \\
\text { patients, including skin and melanoma, } \\
\text { hematology, and sarcoma patients; and } \\
\text { prior experience in working with AYA } \\
\text { patients over the past } 12 \text { months }\end{array}$ & $\begin{array}{l}\text { intervention as a valued way for parents } \\
\text { to respect and support AYA privacy and } \\
\text { independence); and 3) AYAs' ability to } \\
\text { participate in the intervention during the } \\
\text { acute phase of transplant (influence of } \\
\text { symptoms on TMV participation, AYAs' } \\
\text { participation decisions, and suggestions } \\
\text { for TMV improvement) } \\
\text { Results illustrate that with a strong } \\
\text { focus on survival and physical well-being, } \\
\text { professionals significantly underestimate } \\
\text { the breadth of AYA psychosocial } \\
\text { concerns. The findings further indicate } \\
\text { that young people report different } \\
\text { health care preferences compared with } \\
\text { those reported by professionals; there } \\
\text { are varying levels of professional skill, } \\
\text { experience, and confidence; there are } \\
\text { significant workforce development and } \\
\text { support needs for professionals; and } \\
\text { AYA models of care require rigorous } \\
\text { evaluation to ensure the improvement } \\
\text { of outcomes for young people living } \\
\text { with cancer }\end{array}$ & $\begin{array}{l}\text { Young people report different } \\
\text { health care preferences from } \\
\text { those perceived as important } \\
\text { by health care professionals, } \\
\text { and that there are varying } \\
\text { levels of skill and understanding } \\
\text { across professional groups in } \\
\text { relation to AYA care. However, } \\
\text { there was broad recognition } \\
\text { among professionals of the } \\
\text { challenges and the accumulative } \\
\text { emotional impact of working } \\
\text { in this field of complex, clinical, } \\
\text { multidisciplinary practice. This } \\
\text { highlighted the workforce } \\
\text { development and support } \\
\text { needs of professionals working } \\
\text { in this field }\end{array}$ \\
\hline
\end{tabular}

survivors, and church as primary sources of support, when present, contributed to improved QoL..$^{23,37,40}$ Belonging to a support group and engaging in physical activity were associated with reduced distress. ${ }^{36,40}$

\section{Stakeholder perceptions}

Although health care professionals were likely to underestimate or misjudge the health preferences and support needs of AYAs, these perceptions varied across disciplines and levels of experience. ${ }^{44,45}$ Health care professionals agreed on the challenge of addressing unique developmental characteristics of this population. ${ }^{44,45}$ Siblings of AYA survivors experienced high levels of psychological distress that were comparable with the AYA survivor and much greater than the general population. ${ }^{30}$ Similarly, parents and caregivers of AYAs reported negative QoL issues such as ongoing negative emotions related to diagnosis and discussion of diagnosis. ${ }^{41}$
Connectedness and communication were perceived as positive, and the presence of the "nuclear family" led to greater QoL. ${ }^{41}$ Maternal beliefs related to health care influenced the mother's well-being and involvement in the AYA's health care; however, the impact of parental involvement on the offspring's development and autonomy was not reported. ${ }^{46}$

\section{Discussion}

This systematic review sought to identify key psychosocial factors impacting QoL in AYA oncology populations, specifically factors in the context of age, stakeholder perceptions, AYA perceptions, and outcomes (eg, QoL, adjustment). There is a paucity of research from randomized controlled trials or interventions providing evidence of factors affecting QoL in AYA cancer patients or interventions that may improve QoL. Results from this review highlight that AYAs report lower QoL than their healthy peers and older cancer survivors. 
There is a significant amount of unmet needs in the AYA population, including long-term survivorship care, fertility preservation, and mental health services. Results also show that AYAs receive insufficient information on cancer impact on fertility, body image, relationships, and financial assistance. Parents, siblings, and partners of AYA with cancer also report varying positive and negative experiences with information and communication needs and distress. Although health care providers tend to underestimate or misjudge the health preferences and support needs of AYAs, they appear to agree that AYA cancer patients present a unique challenge that most institutions are not prepared to handle. ${ }^{44}$

Some organizations have developed guidelines specific to AYA populations. The Canadian health care system has developed a set of AYA recommendations to improve QoL. ${ }^{47}$ These include the following sections: 1) Active Therapy and Supportive Care, 2) Psychosocial Needs, 3) Palliation and Symptom Management, 4) Survivorship, 5) Research and Metrics, and 6) Awareness and Advocacy. In addition, the National Comprehensive Cancer Network has issued clinical practice guidelines for AYAs with cancer. ${ }^{48}$ These guidelines include: 1) management of AYA patients with cancer: special considerations, 2) psychosocial and behavioral issues, 3) survivorship issues, and 4) palliative and end-of-life care.

There is clear agreement on AYA psychosocial needs and survivorship issues across these two guidelines. Most health care institutions have recognized the need for improvements in AYA care and are developing AYA-specific programs to approach this area of need. ${ }^{49}$ AYA-specific programs should include a multidisciplinary team with specialized skills, including an "AYA champion" (a highly motivated individual with a professional interest in cancer who is often affiliated with complementary programs such as AYA oncology or survivorship), mental health professionals, peer support groups, reproductive endocrinologists, and religious and legal counsels, among others. ${ }^{49}$ In addition, the AYA population represents a significant percentage of patients and is a source of revenue for both pediatric and adult institutions. ${ }^{49}$ Creating AYA-specific programs is a benefit for both the population and health care institution.

Evidence from this systematic review suggests there is a wide age range used for describing the AYA population and an equally wide range of measurement strategies for assessing QoL. Nightingale et $\mathrm{al}^{50}$ reviewed the literature on health-related QoL in young adult survivors of childhood cancer and concluded that the traditional domains assessed in QoL are not comprehensive enough for the AYA population. Huang et $\mathrm{al}^{51}$ examined the psychometric properties of QoL instruments typically used with the AYA population. The study concluded poor discernibility between homogeneous and heterogeneous domains on the instruments in relation to AYA survivors. Quinn et $\mathrm{l}^{52}$ conducted qualitative interviews with 30 participants from the Nightingale et al ${ }^{50}$ study and identified three key content areas missing from traditional QoL measures. These areas included perceived sense of self, relationships, and parenthood. The study further noted that existing QoL instruments do not take into account the impact of a cancer diagnosis on the interrelationship between emotional development and dependence on caregivers.

\section{Limitations}

Our study has several limitations. This search did not assess the quality of studies included in the review; thus, all articles are treated as equally credible, having met the criteria of being published in a peer-reviewed journal. In addition, there was significant variation in the design and methods of studies included in this review. The search strategy was limited to three databases and restricted to English language studies only, which may be a further limitation of this review. Due to methodological variations across studies focusing on the AYA population, it can be problematic to generalize results.

\section{Conclusion}

The literature is lacking in sufficient evidence-based interventions to improve QoL in AYA cancer populations. Further, the tools to adequately measure QoL in this population are also unsatisfactory, and in several cases do not comprehensively target QoL domains relevant to AYA populations. The literature, however, consistently shows agreement regarding the unique needs of this population, indicating a trend toward health care standardization within age ranges or life stages. We suggest the need for AYA-specific programs in health care institutions that comprise a multidisciplinary team that addresses all the unique medical and QoL needs of AYAs.

\section{Disclosure}

The authors report no conflicts of interest in this work.

\section{References}

1. Geue K, Richter D, Schmidt R, et al. The desire for children and fertility issues among young German cancer survivors. J Adolesc Health. 2014;54(5):527-535.

2. Zebrack BJ, Casillas J, Nohr L, et al. Fertility issues for young adult survivors of childhood cancer. Psychooncology. 2004;13(10):689-699.

3. Bellizzi KM, Smith A, Schmidt S, et al. Positive and negative psychosocial impact of being diagnosed with cancer as an adolescent or young adult. Cancer. 2012;118(20):5155-5162. 
4. Quinn GP, Devin M, Fortier MA, et al. Quality of life tools and young adult survivors of pediatric cancer: a commentary on the need to examine perceptions of romantic relationships. J Adolesc Young Adult Oncol. 2014;3(1):47-49.

5. Smith AW, Belizzi KM, Keegan THM, et al. Health-related quality of life of adolescent and young adult patients with cancer in the United States: the Adolescent and Young Adult Health Outcomes and Patient Experience study. J Clin Oncol. 2012;21(17):2136-2147.

6. Smith AW, Parsons HM, Kent EE, et al. Unmet support service needs and health-related quality of life among adolescents and young adults with cancer: the AYA HOPE study. Front Oncol. 2013;3(75): $1-11$.

7. Treadgold CL, Kuperberg A. Been there, done that, wrote the blog: the choices and challenges of supporting adolescents and young adults with cancer. J Clin Oncol. 2010;28(32):4842-4849.

8. Centers for Disease Control and Prevention. Health-Related Quality of Life (HRQOL). Available from: http://www.cdc.gov/hrqol/concept. htm. Accessed December 11, 2014.

9. Klosky JL, Howell CR, Li Z, et al. Risky health behavior among adolescents in the childhood cancer survivor study cohort. $J$ Pediatr Psychol. 2012;37(6):634-646.

10. Hollen PJ, Hobbie WL. Decision making and risk behaviors of cancersurviving adolescents and their peers. J Pediatr Oncol. 1996;13(3): 121-133.

11. Carpentier MY, Mullins LL, Elkin TD, Wolfe-Christensen C. Prevalence of multiple health-related behaviors in adolescents with cancer. J Pediatr Hematol Oncol. 2008;30(12):902-907.

12. Cox CL, McLaughlin RA, Rai SN, et al. Adolescent survivors: a secondary analysis of a clinical trial targeting behavior change. Pediatr Blood Cancer. 2005;45(2):144-154.

13. National Cancer Institute at the National Institutes of Health Adolescents and Young Adults with Cancer. 2014. Available from: http://www.cancer.gov/cancertopics/aya. Accessed December 11, 2014.

14. The LIVESTRONG Foundation. The LIVESTRONG Young Adult Alliance. 2012. Available from: http://www.livestrong.org/what-we-do/ our-actions/programs-partnerships/livestrong-young-adult-alliance/. Accessed December 11, 2014

15. World Health Organization. Adolescents: Health Risks and Solutions. 2014. Available from: http://www.who.int/mediacentre/factsheets/ fs345/en/. Accessed December 11, 2014.

16. Thomas DM, Albritton KH, Ferrari A. Adolescent and young adult oncology: an emerging field. J Clin Oncol. 2010;28(32):4781-4782.

17. D'Agostino NM, Penney A, Zebrack B. Providing developmentally appropriate psychosocial care to adolescent and young adult cancer survivors. Cancer. 2011;117(10):2329-2334.

18. Arnett JJ. Emerging adulthood: a theory of development from the late teens through the twenties. Am Psychol. 2000;55(5):469-480.

19. Morgan S, Davies S, Palmer S, Plaster M. Sex, drugs, and rock ' $n$ ' roll: caring for adolescents and young adults with cancer. J Clin Oncol. 28(32):4825-4830.

20. Nolan VG, Krull KR, Gurney JG, et al. Predictors of future healthrelated quality of life in survivors of adolescent cancer. Pediatr Blood Cancer. 2014;61(10):1891-1894.

21. Shaw GM. Having Children After Cancer: How to Make Informed Choices Before and After Treatment and Build the Family of Your Dreams. 1st ed. Berkeley, CA: Celestial Arts; 2011.

22. Evan EE, Kaufman M, Cook AB, Zeltzer LK. Sexual health and selfesteem in adolescents and young adults with cancer. Cancer. 2006; 107(7 Suppl):1672-1679.

23. Zebrack B, Kent EE, Keegan TH, et al. "Cancer sucks," and other ponderings by adolescent and young adult cancer survivors. JPsychosoc Oncol. 2014;32(1):1-15.

24. Côté L, Turgeon J. Appraising qualitative research articles in medicine and medical education. Med Teach. 2005;27(1):71-75.

25. Kuper A, Lorelei L, Levinson W. Critically appraising qualitative research. BML. 2008;337:a1035.
26. Sanderson S, Tatt ID, Higgins JP. Tools for assessing quality and susceptibility to bias in observational studies in epidemiology:a systematic review and annotated bibliography. Int $J$ Epidemiol. 2007;36(3):666-676.

27. Jack L Jr, Hayes SC, Scharalda JG, et al. Appraising quantitative research in health education:guidelines for public health educators. Health Promot Pract. 2010;11(2):161-165.

28. Kirchhoff AC, Spraker-Perlman HL, McFadden M, et al. Sociodemographic disparities in quality of life for survivors of adolescent and young adult cancers in the Behavioral Risk Factor Surveillance System. J Adolesc Young Adult Oncol. 2014;3(2):66-74.

29. Geue K, Sender A, Schmidt R, et al. Gender-specific quality of life after cancer in young adulthood: a comparison with the general population. Qual Life Res. 2014;23(4):1377-1386.

30. Santacroce SJ, Crandell JB. Feasibility and preliminary findings from a pilot study of allostatic load in adolescent-young adult childhood cancer survivors and their siblings. J Pediatr Oncol Nurs. 2014;31(3): 122-134.

31. Smith AW, Bellizzi KM, Keegan TH, et al. Health-related quality of life of adolescent and young adult patients with cancer in the United States: the Adolescent and Young Adult Health Outcomes and Patient Experience study. J Clin Oncol. 2013;31(17):2136-2145.

32. Phillips-Salimi CR, Andrykowski MA. Physical and mental health status of female adolescent/young adult survivors of breast and gynecological cancer: a national, population-based, case-control study. Support Care Cancer. 2013;21(6):1597-1604.

33. Kazak AE, Derosa BW, Schwartz LA, et al. Psychological outcomes and health beliefs in adolescent and young adult survivors of childhood cancer and controls. J Clin Oncol. 2010;28(12):2002-2007.

34. El-Jawahri A, Pidala J, Inamoto Y, et al. Impact of age on quality of life, functional status, and survival in patients with chronic graft-versus-host disease. Biol Blood Marrow Transplant. 2014;20(9):1341-1348.

35. Keegan TH, Lichtensztajn DY, Kato I, et al. Unmet adolescent and young adult cancer survivors information and service needs: a populationbased cancer registry study. J Cancer Surviv. 2012;6(3):239-250.

36. Brunet J, Love C, Ramphal R, Sabiston CM. Stress and physical activity in young adults treated for cancer: the moderating role of social support. Support Care Cancer. 2014;22(3):689-695.

37. Kent EE, Smith AW, Keegan TH, et al. Talking about cancer and meeting peer survivors: social information needs of adolescents and young adults diagnosed with cancer. $J$ Adolesc Young Adult Oncol. 2013;2(2):44-52.

38. Dyson GJ, Thompson K, Palmer S, et al. The relationship between unmet needs and distress amongst young people with cancer. Support Care Cancer. 2012;20(1):75-85.

39. Zebrack B, Chesler MA, Kaplan S. To foster healing among adolescents and young adults with cancer: what helps? What hurts? Support Care Cancer. 2010;18(1):131-135.

40. Cooke L, Chung C, Grant M. Psychosocial care for adolescent and young adult hematopoietic cell transplant patients. J Psychosoc Oncol. 2011;29(4):394-414.

41. Casillas J, Kahn KL, Doose M, et al. Transitioning childhood cancer survivors to adult-centered healthcare: insights from parents, adolescent, and young adult survivors. Psychooncology. 2010;19(9):982-990.

42. Cohen-Gogo S, Marioni G, Laurent S, et al. End of life care in adolescents and young adults with cancer: experience of the adolescent unit of the Institut Gustave Roussy. Eur J Cancer. 2011;47(18): 2735-2741.

43. Parsons HM, Harlan LC, Lynch CF, et al. Impact of cancer on work and education among adolescent and young adult cancer survivors. J Clin Oncol. 2012;30(19):2393-2400.

44. Zebrack B, Bleyer A, Albritton K, et al. Assessing the health care needs of adolescent and young adult cancer patients and survivors. Cancer. 2006;107(12):2915-2923

45. Thompson K, Dyson G, Holland L, Joubert L. An exploratory study of oncology specialists' understanding of the preferences of young people living with cancer. Soc Work Health Care. 2013;52(2-3):166-190. 
46. Doshi K, Kazak AE, Derosa BW, et al. Measuring health-related beliefs of mothers of adolescent and young adult childhood cancer survivors. Fam Syst Health. 2011;29(1):55-63.

47. Fernandez C, Fraser GAM, Freeman C, et al. Principles and recommendations for the provision of healthcare in Canada to adolescent and young adult-aged cancer patients and survivors. J Adolesc Young Adult Oncol. 2011;1(1):53-59.

48. National Comprehensive Cancer Network, Inc. NCCN Guidelines for Patients: Caring for Adolescents and Young Adults. 2003. Available from: http://www.nccn.org/patients/guidelines/aya/index.html. Accessed on December 11, 2014.

49. Reed D, Block R, Johnson R. Creating an adolescent and young adult cancer program: lessons learned from pediatric and adult oncology practice bases. J Natl Compr Canc Netw. 2014;12:1409-1415.

50. Nightingale CL, Quinn GP, Shenkman EA, et al. Health-related quality of life of young adult survivors of childhood cancer: a review of qualitative studies. J Adolesc Young Adult Oncol. 2011;1(3): 124-132.

51. Huang IC, Quinn GP, Krull K, et al. Head-to-head comparisons of quality of life instruments for young adult survivors of childhood cancer. Support Care Cancer. 2012;20(9):2061-2071.

52. Quinn GP, Huang IC, Murphy D, et al. Missing content from healthrelated quality of life instruments: interviews with young adult survivors of childhood cancer. Qual Life Res. 2013;22(1):111-118.

53. Patient-Centered Outcomes Research Institute. Methodological standards and patient-centeredness in comparative effectiveness research: The PCORI perspective. Journal of the American Medical Association. 2012;307(15), 1636-1640.

54. Selby JV, Beal AC, Frank L. The Patient-Centered Outcomes Research Institute (PCORI) national priorities for research and initial research agenda. Journal of the American Medical Association. 2012; 307(15):1583-1584.

55. Varni JW, Limbers C, Burwinkle TM: Literature review: Health-related quality of life measurement in pediatric oncology: Hearing the voices of the children. J Pediatr Psychol. 2007;32:1151-1163.

56. Ware JE, Kosinski M, Turner-Bowker DM, et al. How to Score Version 2 of the SF-12 Health Survey (with a supplement documenting version 1). Lincoln, RI, QualityMetric, 2002.

57. Kwak M, Zebrack BJ, Meeske KA, et al. Trajectories of Psychological Distress in Adolescent and Young Adult Patients With Cancer: A 1-Year Longitudinal Study. JCO 2013;31(17): 2160-2166.

58. Tedeschi RG, Calhoun LG. Trauma \& Transformation: Growing in the Aftermath of Suffering. Sage Publications, Inc; 1995.

59. Arpawong TE, Oland A, Milam JE, et al. Post-traumatic growth among an ethnically diverse sample of adolescent and young adult cancer survivors. Psycho-Onco. 2013;22(10):2235-2244.

60. Haase JE, Kintner EK, Monahan PO, et al. The Resilience in Illness Model, Part 1 Exploratory Evaluation in Adolescents and Young Adults With Cancer. Cancer Nursing. 2014;37(3):E1-12.

61. Love B, Crook B, Thompson CM, et al. Exploring Psychosocial Support Online: A Content Analysis of Messages in an Adolescent and Young Adult Cancer Community. Cyberpsychology, Behavior, and Social Networking, 2012;15(10):555-559.

62. Stern M, Krivoy E, Foster RH, et al. Psychosocial Functioning and Career Decision-Making in Israeli Adolescent and Young Adult Cancer Survivors. Pediatr Blood Cancer 2010;55:708-713.

63. Varni JW, Seid M, Kurtin PS. PedsQLTM 4.0: Reliability and validity of the Pediatric Quality of Life InventoryTM 4.0 generic core scales in healthy and patient populations. Med Care. 2001;39:800-812.

64. Schwartz LA, Kazak AE, DeRosa BW, et al. The Role of Beliefs in the Relationship Between Health Problems and Posttraumatic Stress in Adolescent and Young Adult Cancer Survivors. J Clin Psychol Med Settings. 2012;19(2):138-146.

65. Schwartz LA, Mao JJ, DeRosa BW, et al. Self-reported health problems of young adults in clinical settings: survivors of childhood cancer and healthy controls. Journal of the American Board of Family Medicine. 2010.23:306-314.
66. DeRosa BW, Kazak AE, Doshi K, et al. Development and validation of the Health Competence Beliefs Inventory in young adults with and without a history of childhood cancer. Annals of Behavioral Medicine. 2011;41,48-58.

67. Kazak AE, Alderfer MA, Streisand R, et al. Treatment of posttraumatic stress symptoms in adolescent survivors of childhood cancer and their families: A randomized clinical trial. Journal of Family Psychology. 2004; $18: 493-504$

68. Dyson GJ, Thompson K, Palmer S, et al. The relationship between unmet needs and distress amongst young people with cancer. Support Care Cancer. 2012;20(1):75-85.

69. O’Callaghan C, Barry P, Thompson K. Music's relevance for adolescents and young adults with cancer: a constructivist research approach. Support Care Cancer. 2012;20(4):687-697.

70. Carpentier MY, Fortenberry JD, Ott MA, et al. Perceptions of masculinity and self-image in adolescent and young adult testicular cancer survivors: implications for romantic and sexual relationships. Psychooncology. 2011;20(7):738-745.

71. Derogatis L. BSI-18 administration and scoring procedures manual. Minneapolis, MN: National Computer Systems. 2000.

72. Pynoos R, Rodriguez N, Steinberg A, Stuber M, Frederick C. UCLA PTSD index for DSM-IV: Adolescent version. Los Angeles: University of California at Los Angeles Trauma Psychiatry Service. 1998.

73. Walker S, Sechrist K, Pender N. Health promoting lifestyle: Development and psychometric characteristics. Nursing Research. 1987;36,76-81.

74. Seeman T, McEwen B, Rowe J, Singer B. Allostatic load as a marker of cumulative biological risk: MacArthur studies of successful aging. Proceedings of the National Academy of Sciences USA. 2001;98: $4770-4775$.

75. Love B, Moskowitz MC, Crook B, et al. Defining adolescent and young adult (AYA) exercise and nutrition needs: concerns communicated in an online cancer support community. Patient Educ Couns. 2013;92(1): $130-133$.

76. Burns DS, Robb SL, Phillips-Salimi C, et al. Parental perspectives of an adolescent/young adult stem cell transplant and a music video intervention. Cancer Nurs. 2010;33(4):E20-E27.

77. Colaizzi PE. Psychological Research as the Phenomenologist Views It. New York, NY: Oxford University Press; 1978.

78. Clinton-McHarg T, Carey M, Sanson-Fisher R, et al. Preliminary development and psychometric evaluation of an unmet needs measure for adolescents and young adults with cancer: the Cancer Needs Questionnaire-Young People (CNQ-YP). Health Qual Life Outcomes. 2012;10:13.

79. Spielberger C, Gorsuch R, Lushene R. Manual for the State-Trait Anxiety Inventory. Consulting Psychologists Press; Palo Alto, CA: 1970.

80. Weathers F, Ford J. Psychometric review of the PTSD Checklist. In: Stamm, BH., editor. Measurement of stress, trauma, and adaptation. Sidran Press; Lutherville, MD:1996. 250-251.

81. Ware J, Kosinski M, Keller S. A 12-item Short-Form Health Survey: Construction of scales and preliminary tests of reliability and validity. Medical Care. 1996;34(3):220-233.

82. Docherty SL, Robb SL, Phillips-Salimi C, et al. Parental perspectives on a behavioral health music intervention for adolescent/young adult resilience during cancer treatment: report from the children's oncology group. J Adolesc Health. 2013;52(2):170-178.

83. Banner L, Mackie E, Hill J. Family relationships in survivors of childhood cancer: Resources or restraint? Patient Education and Counseling. 1996;28:191-199.

84. Palmer S, Mitchell A, Thompson K, Sexton M. Unmet needs among adolescent cancer patients: A pilot study. Palliative and Supportive Care. 2007;5(2):127-134 
Patient Related Outcome Measures

Dovepress

\section{Publish your work in this journal}

Patient Related Outcome Measures is an international, peer-reviewed, open access journal focusing on treatment outcomes specifically relevant to patients. All aspects of patient care are addressed within the journal and practitioners from all disciplines are invited to submit their work as well as healthcare researchers and patient support groups.

Submit your manuscript here: http://www.dovepress.com/patient-related-outcome-measures-journal
The manuscript management system is completely online and includes a very quick and fair peer-review system. Visit http://www.dovepress. com/testimonials.php to read real quotes from published authors. 